\title{
Aggregate and Idiosyncratic Risk in a Frictional Labor Market
}

\author{
Leena Rudanko*
}

This version: July 2008, First version: August 2006

\begin{abstract}
Economists face difficulties explaining the strong cyclicality of US unemployment. This paper contributes both by developing modeling tools and evaluating a potentially important explanation. The paper develops a parsimonious equilibrium model of job search with aggregate productivity shocks, where i) workers face incomplete markets, and ii) wages are determined via optimal long-term contracts. Despite the large state space associated with long-term contracting, the equilibrium has a simple representation as a small system of differential equations. Incomplete markets amplify fluctuations in unemployment, and the results suggest an upper bound on how far they can go in explaining unemployment cyclicality.

Keywords: Unemployment, Wages, Business Cycles, Search, Dynamic Contracts, Incomplete Markets

JEL Classification: D52, E24, E32, J41, J64
\end{abstract}

Unemployment is strongly cyclical in the United States, varying by twenty percent over the business cycle. Economists developing models of unemployment face difficulties explaining this. The cyclical variation in measured labor productivity is ten times smaller, leading us to expect much smaller fluctuations in unemployment than observed. Hall (2005) and Shimer (2005a) discuss this in the context of the widely-used Mortensen-Pissarides search and matching model of unemployment (Pissarides 1985, Mortensen and Pissarides 1994).

There is an important feature of labor markets which the Mortensen-Pissarides model abstracts from entirely - that workers cannot insure against the risk of job-loss nor the subsequent duration of unemployment. Workers are modeled either as risk neutral or fully insured against idiosyncratic unemployment risk. At the same time, empirical evidence suggests that only a fraction of the population hold financial wealth allowing for short term consumption smoothing (Mankiw and Zeldes 1991) and a significant share appear to be liquidity constrained 1 Chetty (2008) shows that approximately half of unemployment benefit claimants in the US held no liquid wealth at the time of

*Boston University, Department of Economics, 270 Bay State Road, Boston, MA 02215, rudanko@bu.edu. This paper is based on the second essay of my dissertation at the University of Chicago. I am grateful for the comments of Daron Acemoglu, Fernando Alvarez, Simon Gilchrist, Francois Gourio, Lars P. Hansen, Robert King, Philipp Kircher, Robert Lucas, Robert Shimer, anonymous referees, as well as seminar audiences.

${ }^{1}$ Hall and Mishkin (1982), Zeldes (1989), Campbell and Mankiw (1990) and others. 
job loss and exhibit liquidity constrained behavior. The data suggest that the level of unemployment benefits has a significant impact on the drop in consumption upon an unemployment shock, more so than the impact on permanent income would suggest (Browning and Crossley 2001, Gruber 1997) 2 These observations are important because the labor market equilibrium in a search model is directly affected by the behavior of unemployed agents. If the full-insurance assumption is not supported by the data, it is important to consider relaxing it in the model.

I show that when workers cannot smooth consumption privately, cyclical fluctuations in unemployment are amplified compared to a complete markets environment. The changes in dynamics are due to changes in how workers value wages. When workers cannot smooth their consumption across unemployment and employment spells, they benefit less from a high wage. This distorts the workers' job search behavior, causing the equilibrium to shift toward lower wages. In periods when high productivity bids up the wage level, the distortion increases, curbing the wage increase relative to a complete markets environment. Conversely, in periods when low productivity causes the wage level to fall, the distortion relaxes, curbing the wage decrease. Because the wage level responds less to changes in productivity in this environment, vacancy-creation responds more 3

The above considerations also suggest role for long-term wage contracts as a substitute for participation in asset markets within an employment relationship. Instead of the usual assumption that wages are an outcome of bilateral bargaining between worker and employer, repeated each period, this paper advances a theory of long-term wage contracting, in the spirit of the implicit contracts literature (Azariadis 1975, Baily 1974). The evidence on individual wages offers support for such a view: For example, Beaudry and DiNardo (1991) and McDonald and Worswick (1999) argue that aggregate conditions at the time of hiring appear to have persisting effects on individual wages. Guiso, Pistaferri, and Schivardi (2005) present evidence supporting the insurance role of wages using matched worker-firm data. This paper hence contributes also to the modeling of wage-setting over the business cycle 4

The contribution of the paper is two-fold: First, I develop a tractable general equilibrium search and matching model where workers face uninsured idiosyncratic labor market risk 5 In the model entrepreneurs use optimal dynamic long-term contracts to attract workers, with equilibrium wages depending both on the current state of the economy, as well as conditions at the time of hiring. From a methodological standpoint, the paper shows that embedding optimal dynamic contracting and directed search into a business cycle model of frictional labor markets with risk averse agents and incomplete markets can yield a tractable framework, with flexibility for extensions. In particular there is no need to restrict the analysis to steady-states, as transitional dynamics are straightforward to tackle. Second, I use the framework to evaluate the quantitative impact of incomplete markets on the business cycle dynamics of unemployment.

\footnotetext{
${ }^{2}$ Jappelli (1990) documents that the unemployed are less likely to have access to credit than the average consumer.

${ }^{3}$ In the terminology of the Mortensen-Pissarides model, the incomplete markets mechanism has the effect of endogenously lowering the bargaining power of workers in wage negotiations, and rendering it counter-cyclical.

${ }^{4}$ Boldrin and Horvath (1995) embedded long-term contracting based on risk sharing motives into a real business cycle model, showing that it improves the ability of the model to explain labor market variables. While in their model long-term contracts were one period ahead contracts, here a contract lasts until a separation shock terminates it. See also Danthine and Donaldson (1992), Gomme and Greenwood (1995), and Sigouin (2004) for alternative approaches.

${ }^{5}$ Storesletten, Telmer, and Yaron (2004) argue that idiosyncratic earnings risk is counter-cyclical in nature. In the model the idiosyncratic risk is counter-cyclical, because a separation shock leads to an unemployment spell with reduced consumption for a period of uncertain duration, shorter in booms and longer in recessions.
} 
The model is an extension of the Mortensen-Pissarides framework. The economy is populated by risk averse workers and entrepreneurs, distinguished by their ability to access capital markets. While entrepreneurs have access to complete asset markets, workers are excluded from asset markets completely, consuming their income each period. This extreme form of market incompleteness delivers significant parsimony in the model.

Entrepreneurs operate a production technology requiring worker labor as input. The technology is subject to both aggregate productivity shocks as well as idiosyncratic separation shocks, leading to an employment relationship becoming unproductive, and the parties separating. Search frictions prevent workers from finding a new job immediately, and while unemployed, they survive on a home production technology.

The equilibrium is a contract posting equilibrium in the spirit of the competitive search equilibrium of Moen (1997), which I extend to a dynamic environment 6 To attract workers, entrepreneurs pay a cost to post vacancies. A vacancy specifies a long-term wage contract, which the entrepreneur is free to choose. Unemployed workers observe all the contracts offered, and choose one to apply for. The choice is based on evaluating both the utility value of the contract, as well as the rate at which the worker expects to find a job with this contract.

At first blush solving for equilibrium outside of steady-state appears intractable because of a large state space of wage contracts assigned to workers upon hiring. Not only does each contract specify a large amount of information about wages paid in various contingencies, but the terms of these contracts depend on the time of hiring. The equilibrium turns out to have a simple representation, however.

First, I prove that in equilibrium there is a unique optimal contract offered at each instant. This contract has the form of a risk sharing arrangement between the entrepreneur and worker, equating the marginal rates of substitution of the agents across time and states. With time separable constant relative risk aversion preferences, this implies that the consumption growth of the worker co-moves with that of his employer's in a systematic way during a contract.

Second, I show that without loss of generality, I can work with a representative entrepreneur. This implies that the wages of all workers co-move systematically with the consumption of the representative entrepreneur, allowing me to capture the cross sectional wage dispersion arising from differences in aggregate conditions at the time of hiring in a simple way.

Finally, solving for equilibrium requires keeping track of the total extent of wage commitments made by the representative entrepreneur, but not their distribution across workers. With this, the payoff relevant state space collapses into just two endogenous state variables: employment and a measure of the total wage commitments made to the existing workforce. The equilibrium can be represented as a small system of differential equations, the dynamics of which are straightforward to characterize. Examining this system I show that, in an economy without aggregate shocks, there is a unique equilibrium path converging to steady-state.

\footnotetext{
${ }^{6}$ The precursors to the competitive search equilibrium introduced in Moen (1997) are the price and wage posting models of Peters (1991) and Montgomery (1991). Acemoglu and Shimer (1999) and Acemoglu and Shimer (2000) examined related models with wage posting in the presence of risk averse workers, but while they focused on steadystates, this paper concentrates on aggregate dynamics.
} 
Because wage commitments are a state variable, the equilibrium captures the idea that the wages of existing workers affect the labor market for new hires, absent from the standard MortensenPissarides framework. If wage commitments are too high, this will cause a drop in hiring and raise unemployment. The dynamics of wage commitments are slow, making them interesting as a potential source of propagation.

The quantitative results show that the changes in dynamics due to the incomplete markets environment bring the model closer to data both in terms of the volatility of unemployment as well as that of wages. The mechanism leading to these changes, described above, can be demonstrated in the context of the steady-state of the economy, by examining how the incomplete markets environment changes how variables respond to permanent changes in productivity 7 Simulation results based on the full dynamic model show that while the incomplete markets environment leads to a significant increase in the cyclical volatility of unemployment, the changes are relatively moderate in magnitude when compared to the large difference between model and data 8 Given the extreme form of market incompleteness assumed, the results suggest an upper bound on how far incomplete markets alone can go in explaining the unemployment volatility puzzle.

The model allows for preference heterogeneity between workers and entrepreneurs both in discount rates as well as willingness to substitute consumption. I show that the impact of incomplete markets on unemployment hinges on the workers' willingness to substitute consumption, rather than that of entrepreneurs, because they are the ones whose consumption - and job search behavior - is directly affected by the lack of markets. The quantitative results are robust to assuming workers are more impatient than entrepreneurs, a potential explanation for the distribution of wealth in the economy.

The paper proceeds as follows: Section 1 presents the model and defines a contract posting equilibrium. Section 2 derives equilibrium properties. Section 3 analyzes an economy without aggregate shocks, examining both the steady-state and transitional dynamics. Section 4 returns to an environment with aggregate shocks, exploring the quantitative impact of market incompleteness. Section 5 discusses related literature and Section 6 concludes.

\section{$1 \quad$ Model}

Preferences Consider a continuous time economy populated by two types of infinitely lived agents: workers and entrepreneurs. There is a continuum of measure one workers, and a large finite number $N$ entrepreneurs. Both types have identical preferences $E_{0} \int_{0}^{\infty} e^{-\rho t} u(c(t)) d t$, where $u$ is a constant relative risk aversion utility function: $u(c)=\frac{c^{1-\gamma}}{1-\gamma}$, with risk aversion $\gamma>0$, and $c$ consumption of the one good in the economy. The assumption of identical preferences will be relaxed later.

Production Technologies Entrepreneurs have access to a linear technology producing $z(t)$ units of output per worker and unit of time, where $z(t)$ is an aggregate productivity level. Each en-

\footnotetext{
${ }^{7}$ See Section 3.1 for this discussion.

${ }^{8}$ The quantitative results are consistent with what the steady-state predicts, showing that the steady-state is informative even of the magnitudes of responses in the dynamic model.
} 
trepreneur can employ any measure of workers. The technology is subject to match-specific separation shocks, which drop the productivity of a worker with his current employer to zero permanently. These shocks arrive at Poisson rate $\delta$. When not employed, workers can produce at home $b$ units of output per unit of time, where $0<b<z(t)$.

Matching Technology The organization of workers and entrepreneurs into production is hampered by search frictions in the labor market. To find a worker, an entrepreneur must post a vacancy, specifying a wage contract (described shortly). Posting a vacancy costs an entrepreneur $\kappa$ units of output per unit of time. Unemployed workers observe all contracts offered by different entrepreneurs and choose one to apply for. A worker's choice of contract depends both on the utility value of the contract, as well as the job finding rate in the market for that contract. The labor market can be thought of as segmenting into contract-specific sub-markets, with a matching function governing the rate of matching in each market based on the measures of vacancies and job applicants present. This rate is a function of the ratio of vacancies to job seekers in the submarket, denoted $\theta$ and also called market tightness. With a Cobb-Douglas matching function, the job-finding rate is $\mu(\theta)=k \theta^{1-\alpha}$, with $k>0, \alpha \in(0,1)$. The rate at which vacancies are filled is $q(\theta)=\mu(\theta) / \theta$. When deciding on a contract to post, entrepreneurs anticipate that their choice will affect the rate at which they will be able to hire workers, as worker flows depend on the contract offered.

Asset Markets Entrepreneurs can trade in complete asset markets, spanning aggregate risk 9 Let $p(t)$ denote the probability normalized Arrow-Debreu prices in these markets and $W_{0}$ initial financial wealth. Workers are excluded from trade completely, consuming their income each period. The asset markets have zero net supply.

Shock Processes The economy experiences business cycles driven by aggregate shocks to labor productivity. The shocks lead to a procyclical job finding rate $\mu(\theta)$, which leads to business cycle variation in unemployment. The separation rate $\delta$ is constant in the model 10

Labor productivity follows a continuous time stochastic process meant to approximate the labor productivity data reported by the Bureau of Labor Statistics. I model it as a jump process with small jumps. Suppose $z(t)$ is otherwise constant, but with Poisson arrival rate $\eta>0$ aggregate shocks arrive that change the value of $z$. Conditional on a shock, the new value of productivity $z^{\prime}$ satisfies $E\left[z^{\prime}-1 \mid z\right]=\xi(z-1)$ with $\xi \in(0,1)$, and $z$ the old value. I denote by $\mathcal{F}_{t}$ the time $t$ information set capturing the history of the aggregate shock process.

Workers face uninsured idiosyncratic unemployment risk because a separation shock leads to an unemployment spell with reduced consumption. The length of the spell depends on the cyclical job-finding rate. Entrepreneurs do not face corresponding idiosyncratic risk, however. Each entrepreneur employs a measure of workers, so a law of large numbers leads to a depreciation rate

\footnotetext{
${ }^{9}$ Entrepreneurs do not face idiosyncratic risk, as explained below.

${ }^{10}$ This simplifying assumption is motivated by the findings of Shimer (2005b) that cyclical variation in unemployment derives mainly from variation in the job-finding rate, while the separation rate has a significantly smaller impact.
} 
of $\delta$ in the labor force and a hiring rate of $q(\theta)$ in vacancy posting. Entrepreneurs hence only face aggregate risk. Following from this, the model variables are random variables conditional simply on the aggregate shock history captured by $\mathcal{F}_{t} 11$

Wage Contract I denote a wage contract signed at time $t$ given $\mathcal{F}_{t}$, by $\sigma(t)$. The contract is a collection of random variables $w(t, t+s)$ specifying state contingent wage payments for all continuation histories $\mathcal{F}_{t+s}, s \geq 0$ of $\mathcal{F}_{t}$. These payments are conditional on the separation shock not having hit 12 I use $\Sigma(t)$ to denote the set of all such contracts, given a history $\mathcal{F}_{t}$. Entrepreneurs choose an optimal contract from this (large) set, giving them significant freedom in the decision.

Worker Problem The only decision workers make is which contract to apply for when unemployed. They observe the set of available contracts $\sigma^{i}(t)$, as well as the market tightness $\theta^{i}(t)$ in the market for each contract. Their decision takes into account both the utility value of the contract, $E_{t} \int_{0}^{\infty} e^{-(\rho+\delta) s} u\left(w^{i}(t, t+s)\right) d s$, and the job finding rate, $\mu\left(\theta^{i}(t)\right)$.

In principle the equilibrium may feature alternative contracts to choose from 13 with worker flows among these alternative markets adjusting to make workers indifferent among them. For example, if the equilibrium featured both a high wage contract and a low wage contract, then the market for the high wage contract would become congested with many workers applying. In equilibrium workers would be indifferent between finding a low wage job quickly and finding a high wage job slowly. If I define $V^{u}(t)$ to be the utility value of unemployment, it has to satisfy

$$
\begin{array}{r}
\rho V^{u}(t)=u(b)+\mu\left(\theta^{i}(t)\right)\left[E_{t} \int_{0}^{\infty} e^{-(\rho+\delta) s}\left[u\left(w^{i}(t, t+s)\right)+\delta V^{u}(t+s)\right] d s-V^{u}(t)\right] \\
+\eta\left[E_{t,+} V^{u}(t)-V^{u}(t)\right]+\frac{d}{d t} V^{u}(t),
\end{array}
$$

for all available markets $\left(\sigma^{i}(t), \theta^{i}(t)\right)$. As $V^{u}(t)$ does not depend on $i$, this equation captures the idea that the unemployed are indifferent across markets. While unemployed, each worker consumes $b$ and depending on the market he chooses, the job-finding rate is given by $\mu\left(\theta^{i}(t)\right)$, and once employed, the worker consumes wages specified by $\sigma^{i}(t)$ until the separation shock hits and the worker returns to unemployment. Aggregate shocks arrive at rate $\eta$, causing $V^{u}(t)$ to jump. I use the notation $E_{t,+} V^{u}(t)$ for the expected value of unemployment at time $t$, conditional on an aggregate shock hitting at $t$ and history $\mathcal{F}_{t}$. The expectations are taken with respect to the new value of productivity upon a jump.

Entrepreneur Problem Entrepreneurs face a more complicated problem than the workers. As part of the competitive search framework, the entrepreneurs are endowed with a belief function

\footnotetext{
${ }^{11}$ The notation should be interpreted appropriately. For example $p(t)$ is a probability-normalized price of a state contingent claim, whose value depends on $\mathcal{F}_{t}$.

${ }^{12}$ As a simplifying assumption, the possibility of severance pay is ruled out. Empirical evidence suggests severance pay is not dominant: Chetty (2008) examines a pool of unemployed workers and reports that $19 \%$ received severance pay upon job loss. Bishow and Parsons (2004) examine a larger pool of employed workers and report that approximately $24 \%$ had formal severance packages.

${ }^{13}$ The equilibrium turns out to feature a single contract offered at each point, however.
} 
$\Theta: \mathbb{R} \times \mathbb{R} \rightarrow \mathbb{R}_{+}$, which states the entrepreneur's beliefs about the market tightness to prevail in the market for any contract he may contemplate offering, as

$$
\Theta\left(E_{t} \int_{0}^{\infty} e^{-(\rho+\delta) s} u(w(t, t+s)) d s, t\right)
$$

In equilibrium these beliefs must be consistent with worker behavior as discussed above. The belief function is a reflection of equation (11) 14 and is hence decreasing, convex and differentiable in its first argument. It is assumed that for any contract the entrepreneur may consider offering, the expected flow of workers applying for the contract yields a market tightness making workers indifferent between applying for this contract and the alternative contracts available 15

Indexing entrepreneurs by $i=1 \ldots N$, the sequence problem of an entrepreneur at time zero reads: Given the process for prices, $p(t)>0$, and a belief function $\Theta(., t)$ for all $\mathcal{F}_{t}, t \geq 0$, choose $c^{i}(t) \geq 0, v^{i}(t) \geq 0, \sigma^{i}(t) \in \Sigma(t)$ for all $\mathcal{F}_{t}, t \geq 0$, to

$$
\begin{aligned}
& \max E_{0} \int_{0}^{\infty} e^{-\rho t} u\left(c^{i}(t)\right) d t \\
& \text { s.t. } E_{0} \int_{0}^{\infty} p(t)\left[\int_{-\infty}^{t} n^{i}(\tau, t)\left[z(t)-w^{i}(\tau, t)\right] d \tau-\kappa v^{i}(t)-c^{i}(t)\right] d t+W_{0}^{i}=0 \\
& \quad n^{i}(\tau, t)=e^{-\delta t} n^{i}(\tau, 0) \text { for } \tau<0 \\
& \quad n^{i}(\tau, t)=e^{-\delta(t-\tau)} q\left(\Theta\left(E_{\tau} \int_{0}^{\infty} e^{-(\rho+\delta) s} u\left(w^{i}(\tau, \tau+s)\right) d s, \tau\right)\right) v^{i}(\tau) \text { for } \tau \geq 0 \\
& \quad \text { with } W_{0}^{i}, n^{i}(\tau, 0), \sigma^{i}(\tau) \text { given for all } \tau<0
\end{aligned}
$$

The initial conditions concern the size and composition of the initial workforce, corresponding wage contracts, and the entrepreneur's initial financial wealth. Here $n^{i}(\tau, 0)$ denotes the measure of workers hired in period $\tau<0$ who are still working in period zero and $\sigma^{i}(\tau)$ is the contract they were hired with 16 The choice variables are the measures of vacancies to post $v^{i}(t)$, the wage contracts $\sigma^{i}(t)$ to offer, as well as the entrepreneur's consumption $c^{i}(t)$. Implicit is also a choice of trades in the asset market.

Equation (2) is a present value budget constraint. Note that prices are normalized by probabilities, so taking expectations gives the correct summation over states. Each period $t$ the entrepreneur has production output $\int_{-\infty}^{t} n^{i}(\tau, t) z(t) d \tau$ due to the workforce hired in periods $\tau \in(-\infty, t]$. Workers are paid according to their contracts, so total wage costs equal $\int_{-\infty}^{t} n^{i}(\tau, t) w^{i}(\tau, t) d \tau$. The entrepreneur also pays the costs of vacancy posting. Equations (3) and (44) are laws of motion for the cohortspecific labor force sizes. The first refers to cohorts hired before time zero and the second to those hired after. Separation shocks depreciate cohorts at rate $\delta$, while total expected hiring in period $\tau$ is given by the term $q\left(\hat{\Theta}\left(\sigma^{i}(\tau), \tau\right)\right) v^{i}(\tau)$ if the measure of vacancies posted is $v^{i}(\tau)$ and the contract offered is $\sigma^{i}(\tau) 17$

\footnotetext{
${ }^{14}$ In equilibrium, the belief function must satisfy equation (1).

${ }^{15}$ This involves an assumption that the individual entrepreneur is small, and cannot influence the market value of unemployment.

${ }^{16}$ For notational convenience I impose that an entrepreneur offers the same contract for all workers hired at a given time. It will become clear later that this is not restrictive since there turns out to be a unique optimal choice.

${ }^{17} \mathrm{I}$ use $\hat{\Theta}\left(\sigma^{i}(\tau), \tau\right)$ as shorthand for $\Theta\left(E_{\tau} \int_{0}^{\infty} e^{-(\rho+\delta) s} u\left(w^{i}(\tau, \tau+s)\right) d s, \tau\right)$.
} 
Next I define a contract posting/competitive search equilibrium for an economy with entrepreneurs indexed by $i=1 \ldots N$, in the spirit of Moen (1997) 18

Definition 1.1. An equilibrium consists of, for all $\mathcal{F}_{t}, t \geq 0$, a price $p(t)>0$, a value of unemployment $V^{u}(t)$ and entrepreneur beliefs $\Theta: \mathbb{R} \times \mathbb{R} \rightarrow \mathbb{R}_{+}$, as well as for each entrepreneur: consumption $c^{i}(t) \geq 0$, measure of vacancies posted $v^{i}(t) \geq 0$, the contract offered $\sigma^{i}(t) \in \Sigma(t)$, along with the corresponding market tightness $\theta^{i}(t)>0$, as well as resulting labor forces $n^{i}(\tau, t) \geq 0$ for $\tau \leq t$ and economy-wide unemployment $n_{u}(t)=1-\sum_{i} \int_{\tau \leq t} n^{i}(\tau, t) d \tau$ such that

1. Entrepreneurs optimize: Given $\{p(t), \Theta(., t)\}$, for all $\mathcal{F}_{t}, t \geq 0$, the allocation $\left\{c^{i}(t), v^{i}(t), \sigma^{i}(t), n^{i}(\tau, t)\right\}$ solves the entrepreneur's problem $(\mathrm{P})$ for all $\mathcal{F}_{t}, t \geq 0, i=1 \ldots N$.

2. Workers optimize and the entrepreneurs' beliefs are consistent with worker flows:

The value of unemployment $V^{u}(t)$, market tightnesses $\theta^{i}(t)$ and contracts $\sigma^{i}(t)$ satisfy

$$
\begin{array}{r}
\rho V^{u}(t)=u(b)+\mu\left(\theta^{i}(t)\right)\left[E_{t} \int_{0}^{\infty} e^{-(\rho+\delta) s}\left[u\left(w^{i}(t, t+s)\right)+\delta V^{u}(t+s)\right] d s-V^{u}(t)\right] \\
+\eta\left[E_{t,+} V^{u}(t)-V^{u}(t)\right]+\frac{d}{d t} V^{u}(t),
\end{array}
$$

for any $\mathcal{F}_{t}, t \geq 0, i=1 \ldots N$. The belief function is defined implicitly such that for any $\sigma(t) \in \Sigma(t)$ and $\mathcal{F}_{t}, t \geq 0$, the value $\theta(t)=\Theta\left(E_{t} \int_{0}^{\infty} e^{-(\rho+\delta) s} u(w(t, t+s)) d s, t\right)$ satisfies

$$
\begin{array}{r}
\rho V^{u}(t)=u(b)+\mu(\theta(t))\left[E_{t} \int_{0}^{\infty} e^{-(\rho+\delta) s}\left[u(w(t, t+s))+\delta V^{u}(t+s)\right] d s-V^{u}(t)\right] \\
+\eta\left[E_{t,+} V^{u}(t)-V^{u}(t)\right]+\frac{d}{d t} V^{u}(t) .
\end{array}
$$

3. Goods market clearing: $\sum_{i}\left[\int_{-\infty}^{t} n^{i}(\tau, t)\left(z(t)-w^{i}(\tau, t)\right) d \tau-\kappa v^{i}(t)-c^{i}(t)\right]=0$, for all $\mathcal{F}_{t}, t \geq 0$ where $w^{i}(\tau, t)$ is specified by $\sigma^{i}(\tau)$.

4. Labor market clearing: $\sum_{i} \frac{v^{i}(t)}{\theta^{i}(t)}=n_{u}(t)$, for all $\mathcal{F}_{t}, t \geq 0$.

Part 2. captures the idea that if the equilibrium features alternative contracts, workers must be indifferent between them. It goes further however, to allow entrepreneurs to consider offering out-ofequilibrium contracts as well. An entrepreneur considering offering an out-of-equilibrium contract is assumed to expect a market tightness making workers indifferent between the new contract and existing equilibrium contracts. In doing so, entrepreneurs take as given the market value of search $V^{u} 19$ There cannot exist an out-of-equilibrium contract giving an entrepreneur higher profits than the equilibrium contracts, while leaving workers indifferent.

\footnotetext{
${ }^{18}$ This definition is complicated by the dynamic structure of the model, but the essence of the definition is exactly the same as in Moen (1997).

One could add the constraint $\sum_{i} W_{0}^{i}=0$, but this is implied by integrating over budget constraints and using goods market clearing:$$
\sum_{i} W_{0}^{i}=E_{0} \int_{0}^{\infty} p(t) \sum_{i}\left[c^{i}(t)-\int_{-\infty}^{t} n^{i}(\tau, t)\left(z(t)-w^{i}(\tau, t)\right) d \tau+\kappa v^{i}(t)\right] d t=0 .
$$

${ }^{19}$ The market is assumed to be competitive in the sense that individual entrepreneurs cannot affect the equilibrium value. This implies an assumption that the entrepreneur cannot deviate from equilibrium by such a large measure of vacancies as to affect the market value of search.
} 


\section{Equilibrium Properties}

This section begins with a useful aggregation result and then gives a system of dynamic equations characterizing equilibrium.

\subsection{Representative Entrepreneur}

It turns out that the analysis can be simplified to a representative entrepreneur, without loss of generality. The results in Lemma 2.1 combine to this aggregation result in Proposition 2.1.

Lemma 2.1. Equilibrium Properties If an equilibrium exists, it has the properties:

1. Unique contract offered: $\sigma^{i}(t)=\sigma(t), \theta^{i}(t)=\theta(t) \forall i=1 \ldots N, \mathcal{F}_{t}, t \geq 0$.

2. Marginal rates of substitution are equated with relative prices for both entrepreneurs and employed workers:

$$
e^{-\rho s}\left(\frac{c^{i}(t+s)}{c^{i}(t)}\right)^{-\gamma}=e^{-\rho s}\left(\frac{w(\tau, t+s)}{w(\tau, t)}\right)^{-\gamma}=\frac{p(t+s)}{p(t)},
$$

for all $i=1 \ldots N, \tau \leq t, s \geq 0$, and all information sets such that $\mathcal{F}_{\tau} \subset \mathcal{F}_{t} \subset \mathcal{F}_{t+s}$.

3. Posting vacancies gives zero profit:

$$
\kappa=q(\theta(t)) E_{t} \int_{0}^{\infty} e^{-\rho s} \frac{p(t+s)}{p(t)}[z(t+s)-w(t, t+s)] d s, \forall \mathcal{F}_{t}, t \geq 0 .
$$

4. Only aggregate measures of vacancies posted and labor force size are determined in equilibrium, not their distribution among entrepreneurs.

The basic ideas underlying these results are simple (Appendix A contains the proofs). Consider the entrepreneur's problem $(\mathrm{P})$ and the hiring decision at any given point in time. The entrepreneur decides what contract $\sigma^{i}(t)$ to offer, and the measure of vacancies to post $v^{i}(t)$. The decision is based on maximizing the budget set of the entrepreneur, taking as given prices and the belief function. Separating from the budget set the (additive) part which is affected by the choice of $\sigma^{i}(t), v^{i}(t)$ one is left with the problem

$$
\max v^{i}(t)\left\{-p(t) \kappa+q\left(\hat{\Theta}\left(\sigma^{i}(t), t\right)\right) E_{t} \int_{0}^{\infty} e^{-\delta s} p(t+s)\left[z(t+s)-w^{i}(t, t+s)\right] d s\right\} .
$$

Notice that this problem is independent of any entrepreneur-specific factors, so if it has a unique solution, that solution must be independent of such factors as well. The term in curly brackets is the present value of profit per vacancy. For any equilibrium contract this term must be zero, otherwise vacancy-posting would be either unbounded or zero. This implies the zero profit condition on vacancy-creation (part 3. of the lemma). 
Equilibrium contracts must maximize profits per vacancy. Substituting in the equilibrium condition (6) governing the beliefs of entrepreneurs, this problem reads: Given $\mathcal{F}_{t}, t \geq 0$, the processes $p(t+s), V^{u}(t+s)$, for all $s \geq 0$, and continuations $\mathcal{F}_{t+s}$, choose $\theta^{i}(t), w^{i}(t, t+s)$, for all $s \geq 0$, and all continuations $\mathcal{F}_{t+s}$ to

$$
\begin{aligned}
& \max -p(t) \kappa+q\left(\theta^{i}(t)\right) E_{t} \int_{0}^{\infty} e^{-\delta s} p(t+s)\left[z(t+s)-w^{i}(t, t+s)\right] d s \\
& \text { s.t. } \\
& \begin{aligned}
\rho V^{u}(t)=u(b)+\mu\left(\theta^{i}(t)\right)\left[E_{t} \int_{0}^{\infty} e^{-(\rho+\delta) s}\left[u\left(w^{i}(t, t+s)\right)+\delta V^{u}(t+s)\right] d s-V^{u}(t)\right] \\
+\eta\left[E_{t,+} V^{u}(t)-V^{u}(t)\right]+\frac{d}{d t} V^{u}(t) .
\end{aligned}
\end{aligned}
$$

In solving this problem entrepreneurs take as given both prices $p(t)$ and the market value of search $V^{u}(t)$. The problem can be separated into two parts: 1) Given a promised utility value of wages to be delivered to a worker, what is the form of the Pareto-efficient contract? 2) Given the form of the efficient contract, what is the optimal utility value that firms should offer workers, to maximize their profit while delivering unemployed workers their market utility $V^{u}$.

To answer the first question, consider taking first order conditions with respect to wages. We obtain the optimality conditions:

$$
e^{-\rho s} \frac{u^{\prime}\left(w^{i}(t, t+s)\right)}{u^{\prime}\left(w^{i}(t, t)\right)}=\frac{p(t+s)}{p(t)},
$$

for all $s>0$ and continuation histories $\mathcal{F}_{t+s}$ of $\mathcal{F}_{t}$. Entrepreneurs face market prices in allocating consumption across time and states and the profit maximizing way of compensating workers involves setting their marginal rates of substitution equal to relative prices. (Recall that the prices $p$ are normalized by probabilities.) Even though workers do not have direct access to trade in the asset market, the optimal wage contract substitutes for this.

The same optimality condition holds for the entrepreneur's own consumption decision as well, so we have $e^{-\rho s} \frac{u^{\prime}\left(c^{i}(t+s)\right)}{u^{\prime}\left(c^{i}(t)\right)}=\frac{p(t+s)}{p(t)}$. This implies part 2. of the lemma.

Turning to the second question, notice that equation (7) implies that once the initial wage level in a contract is pinned down, future wages are determined by market prices. Imposing this structure on contracts, the only remaining issue is the choice of the initial wage level - or utility value offered to workers. This is a one dimensional optimization problem, and whether it has a unique solution hinges on the congestion properties of the market, as captured by the matching function, in the same way as in Moen (1997). A Cobb-Douglas matching function leads to a unique solution characterized by the first order condition

$$
\frac{1-\alpha}{F_{p}(t)}=\frac{\alpha u^{\prime}(w(t, t))}{V(t)-V^{u}(t)}
$$

where

$$
F_{p}(t):=E_{t} \int_{0}^{\infty} e^{-\delta s} \frac{p(t+s)}{p(t)}[z(t+s)-w(t, t+s)] d s
$$


and

$$
V(t):=E_{t} \int_{0}^{\infty} e^{-(\rho+\delta) s}\left[u(w(t, t+s))+\delta V^{u}(t+s)\right] d s .
$$

Equation (81) resembles the surplus division equation of the Mortensen-Pissarides model, except that now the matching function elasticity $\alpha$ plays the role of the worker's share of the match surplus and we have curvature in utility. Upon matching, the entrepreneur gets present value $F_{p}(t)$ and the worker the gain in utility $V(t)-V^{u}(t)$. Choosing the optimal starting wage level involves comparing the percentage gain to the worker from an increase in the wage, $\frac{u^{\prime}(w(t, t))}{V(t)-V^{u}(t)}$, to the corresponding percentage cost to the entrepreneur, $\frac{1}{F_{p}(t)}$. The optimality condition sets their proportions depending on the elasticity of the matching function, capturing the congestion properties of the labor market. The equation captures the tradeoff between delivering workers value through the contract versus faster re-employment. Increasing contract wages leads to diminishing gains in utility, but so does increasing the job-finding rate, due to increased congestion in the market.

Because there is a unique optimal contract, this must be the only equilibrium contract. This implies part 1. of the lemma 20 Finally, there is nothing pinning down how vacancy creation is divided across entrepreneurs.

Lemma 2.1 implies that the distribution of production and consumption among entrepreneurs is not relevant for the evolution of the economy, and the problem can be simplified by aggregating to a representative entrepreneur.

Definition 2.1. A representative entrepreneur equilibrium is an equilibrium with $N=1$.

\section{Proposition 2.1. Aggregation}

(a) Given an equilibrium with $N$ entrepreneurs, the aggregated allocation $c(t):=\sum_{i} c^{i}(t), v(t):=$ $\sum_{i} v^{i}(t), n(t, t+s):=\sum_{i} n^{i}(t, t+s)$ along with $p(t), V^{u}(t), \theta(t), \sigma(t)$ constitutes a representative entrepreneur equilibrium, if the initial conditions of the single entrepreneur are defined as $n(\tau, 0):=\sum_{i} n^{i}(\tau, 0), \sigma(\tau):=\{w(\tau, t) \forall t \geq \tau\}$, with $w(\tau, t):=\frac{1}{n(\tau, 0)} \sum_{i} n^{i}(\tau, 0) w^{i}(\tau, t)$ and $W_{0}:=0$.

(b) Given a representative entrepreneur equilibrium, and individual initial conditions $\left\{\sigma^{i}(\tau), n^{i}(\tau, 0), W_{0}^{i}, \forall \tau<0, i=1 \ldots N\right\}$, that

1. Integrate up to the initial conditions of the representative entrepreneur equilibrium, and

2. For all $i=1 \ldots N$, satisfy

$$
E_{0} \int_{0}^{\infty} p(t)\left[\int_{-\infty}^{0} n^{i}(\tau, t)\left[z(t)-w^{i}(\tau, t)\right] d \tau-\kappa v^{i}(t)\right] d t+W_{0}^{i}>0,
$$

then an equilibrium with $N$ entrepreneurs can be recovered, and it is unique in $c^{i}(t), \theta^{i}(t)=$ $\theta(t), \sigma^{i}(t)=\sigma(t)$ and aggregates $\sum_{i} v^{i}(t), \sum_{i} n^{i}(\tau, t)$ for $\mathcal{F}_{t}, t \geq 0$.

From here on I restrict attention to a representative entrepreneur.

\footnotetext{
${ }^{20}$ Moreover, because this holds independent of initial conditions, even if the economy started out with different contracts, eventually it would converge toward having only contracts of the optimal form.
} 


\subsection{Equilibrium Characterization}

The following proposition gives a set of dynamic equations useful for solving for equilibrium.

\section{Proposition 2.2. Characterization}

(a) If a representative entrepreneur equilibrium exists, then it satisfies the following for all $t, s \geq 0$ and information sets:

1. Wage contracts have form: $w(t, t+s)=a(t) c(t+s)$, for all $t, s \geq 0, \mathcal{F}_{t} \subset \mathcal{F}_{t+s}$.

2. $\frac{1-\alpha}{F(t)}=\frac{\alpha u^{\prime}(w(t, t))}{V(t)-V^{u}(t)}$,

(wage-tightness tradeoff)

3. $\kappa=q(\theta(t)) F(t)$, (zero profit)

4. $c(t)=\int_{-\infty}^{t} n(\tau, t)[z(t)-w(\tau, t)] d \tau-\kappa \theta(t) n_{u}(t)$, (resource constraint)

5. $\rho V^{u}(t)=u(b)+\mu(\theta(t))\left[V(t)-V^{u}(t)\right]+\eta\left[E_{t,+} V^{u}(t)-V^{u}(t)\right]+\frac{d}{d t} V^{u}(t)$, (value of unemployment)

6. $\dot{n}_{u}(t)=-\mu(\theta(t)) n_{u}(t)+\delta\left(1-n_{u}(t)\right)$ (law of motion for unemployment)

where

$$
F(t):=E_{t} \int_{0}^{\infty} e^{-(\rho+\delta) s} \frac{u^{\prime}(c(t+s))}{u^{\prime}(c(t))}[z(t+s)-w(t, t+s)] d s
$$

and

$$
V(t):=E_{t} \int_{0}^{\infty} e^{-(\rho+\delta) s}\left[u(w(t, t+s))+\delta V^{u}(t+s)\right] d s .
$$

(b) If $V^{u}(t), \theta(t)>0, \sigma(t), n(t, t+s), n_{u}(t), c(t)>0$, for all $t, s \geq 0, \mathcal{F}_{t} \subset \mathcal{F}_{t+s}$ satisfy conditions 1.-6. in Proposition 2.2 (a), then they correspond to a unique representative entrepreneur equilibrium (up to price level scaling), with $\frac{p(t+s)}{p(t)}:=e^{-\rho s} \frac{u^{\prime}(c(t+s))}{u^{\prime}(c(t))}$ for the corresponding continuation histories and $v(t):=\theta(t) n_{u}(t)$.

A key part of this characterization result is condition 1. It follows directly from part 2. of Lemma 2.1, which implies that the consumption growth of each employed worker equals that of the representative entrepreneur across time and aggregate contingencies, for as long as the worker remains employed. One way to interpret this is that when a worker is hired in period $t$, the entrepreneur commits to paying a fixed share $a(t)$ of his own consumption to the worker for as long as the worker remains employed.

Condition 2. reflects the division of match surplus between a worker and the representative entrepreneur, familiar from equation (8) . Condition 3 . is the zero profit condition on vacancy creation, condition 4 . the resource constraint, condition 5 . the dynamic equation for the value of unemployment and condition 6 . the law of motion for unemployment.

In what follows I use the equations in Proposition 2.2 to solve for equilibrium. 


\section{The Qualitative Impact of Incomplete Markets}

This section begins by examining the impact of incomplete markets on the steady-state of the economy, including the responses of wages and unemployment to changes in productivity. This discussion captures the key mechanism underlying the quantitative results in the paper. It then proceeds to examine the transitional dynamics of the model, showing that this can be done in a tractable way. The focus is on an environment where productivity $z$ is constant. I show that there is a unique equilibrium path converging to steady-state and illustrate the dynamic interaction of wages and employment.

\subsection{The Steady-State and the Incomplete Markets Mechanism}

In steady-state all workers have the same constant wage $w$. It can be written as $w=a c$, a product of the constant entrepreneur consumption $c$ and the workers' share of this consumption $a$ (though this is not particularly useful here). All workers are hired with the same consumption share as aggregate conditions remain unchanged. The resource constraint implies that $c=\left(1-n_{u}\right)(z-w)-\kappa \theta n_{u}$, where unemployment $n_{u}$ satisfies $n_{u}=\frac{\delta}{\mu(\theta)+\delta}$ (based on the law of motion for unemployment), and $\theta$ is the steady-state market tightness. The tightness is determined by the surplus sharing and zero profit conditions

$$
\frac{1-\alpha}{F}=\frac{\alpha u^{\prime}(w)}{V-V^{u}}, \text { and } \kappa=q(\theta) F,
$$

respectively. Here $F$ is the present discounted value of profits from a new contract, $F=\frac{z-w}{\rho+\delta}$, $V$ the utility value to a worker from a new contract, $V=\frac{u(w)+\delta V^{u}}{\rho+\delta}$, and $V^{u}$ the utility value of unemployment, satisfying $\rho V^{u}=u(b)+\mu(\theta)\left[V-V^{u}\right]$.

These equations reduce to the steady-state equations of the Mortensen-Pissarides model when preferences are linear, if the Hosios (1990)-condition holds i.e. the bargaining share of the worker is equal to the matching function elasticity. Because this condition is commonly imposed in the literature on the Mortensen-Pissarides model, the steady-states of the models generally coincide when $\gamma=0$.

When preferences are not linear, the incomplete markets environment changes how workers value wages. The changes are reflected in the expression for $\frac{u^{\prime}(w)}{V-V^{u}}$, the marginal percentage gain to a newly hired worker from increasing the wage. To see exactly what happens, consider solving for this term as a function of the steady-state wage 21

$$
g(w, \gamma):=\frac{u^{\prime}(w)}{V-V^{u}}=\frac{u^{\prime}(w)}{u(w)-u(b)}\left(\rho+\delta+k\left(\frac{z-w}{\rho+\delta} \frac{k}{\kappa}\right)^{\frac{1-\alpha}{\alpha}}\right)
$$

To relate outcomes to the linear utility case, define further the relative gain $\Delta(w, \gamma):=\frac{g(w, \gamma)}{g(w, 0)}$. The function $\Delta$ has the properties that i) when $\gamma=0, \Delta(w, \gamma)=1$ for all $w \geq b$, and ii) when $\gamma>0$, $\Delta(w, \gamma)=1$ when $w=b$ but decreases strictly in $w$ thereafter (see Appendix C). The function $\Delta$ captures the distortion in the labor market due to workers facing incomplete asset markets:

\footnotetext{
${ }^{21}$ Using the above expression for $V$, equation for $V^{u}$, and zero profit condition.
} 
Workers gain less from any wage $w>b$ than they would under linear preferences, and moreover, this difference increases in both the wage and $\gamma$.

The surplus sharing equation can now be rewritten as $\frac{1-\alpha}{F}=\Delta(w, \gamma) \alpha g(w, 0)$, or

$$
\frac{1-\alpha}{\frac{z-w}{\rho+\delta}}=\Delta(w, \gamma) \frac{\alpha}{\frac{w-b}{\rho+\delta+k\left(\frac{z-w}{\rho+\delta} \frac{k}{\kappa}\right)^{\frac{1-\alpha}{\alpha}}}} .
$$

As $w$ rises from $b$ toward $z$, the left hand side of this equation increases and the right hand side decreases, pinning down a unique steady-state wage $w \in(b, z) 22$ When $\gamma>0$, the decreasing function $\Delta$ distorts the steady-state wage down relative to the case with $\gamma=0$. When workers gain less from a high wage, the equilibrium shifts toward lower wages. Moreover, the size of this distortion increases in $\gamma$.

The impact of incomplete markets on the cyclical properties of the model can be illustrated in this steady-state setting by examining how it affects the responses of model variables to permanent changes in productivity. I will show later that this approach captures the key mechanism for the quantitative results of the paper, computed from the fully dynamic model.

The key observation for business cycles is that the distortion increases in the wage. When steadystate productivity $z$ rises, the steady-state wage will tend to rise. When workers prefer smooth consumption, the wage increase is curbed by the growing distortion, relative to the linear utility environment. To see this in equation (99), note that when $\gamma>0, \Delta$ falls in the wage, while otherwise it is constant. Similarly, when productivity falls, the wage will tend to fall. When workers prefer smooth consumption, this coincides with the distortion relaxing, curbing the wage decrease.

In the language of the Mortensen-Pissarides model, the incomplete markets mechanism has the effect of endogenously reducing the bargaining power of the worker in wage negotiations, and rendering it counter-cyclical. Imposing the incomplete markets framework effectively scales the relative bargaining strength of workers (here the equivalent is $\frac{\alpha}{1-\alpha}$ ) by the steady-state value of $\Delta$, which is less than one and negatively related to the level of productivity.

The connection to the Mortensen-Pissarides model extends beyond the steady-state. This is because the contract posting equilibrium has a close relationship with the equilibrium of an economy with random search and bilateral wage bargaining, as usually seen in the context of the MortensenPissarides model. In particular, if i) the Hosios (1990)-condition holds, and ii) bargaining takes place over the same set of contracts as in the posting equilibrium, then the two are equivalent 23 Because of this, in the risk neutral limit the model inherits the employment dynamics of the MortensenPissarides model. The wage dynamics are different, but in a way which does not matter for employment (under linear preferences). One can easily relate the changes in employment dynamics stemming from incomplete markets to that benchmark by varying the preference parameter $\gamma$. This makes the quantitative results obtained here directly comparable to existing literature discussing the dynamics of the Mortensen-Pissarides model. I show this connection between the models in Appendix E.

\footnotetext{
${ }^{22}$ As long as $z>b$, as assumed.

${ }^{23}$ Note that this assumes bargaining takes place over a set of long-term contracts at the beginning of the match and the parties commit to the contract, as in the contract posting setup.
} 


\subsection{Out of Steady-State Dynamics: Reducing the State Space}

In order to solve for equilibrium outside of steady-state, in principle one needs to keep track of the entire distribution of cohorts of workers, including the contracts assigned to those workers upon hiring 24 Each contract contains a large amount of information, and they differ across cohorts, making the problem appear intractable. I show that it is possible to bypass this problem by using information about the equilibrium to construct a small set of sufficient statistics which are easy to keep track of.

Suppose the economy has been running for a long time, so all existing contracts are of the form: $w(\tau, t)=a(\tau) c(t)$, where $a(\tau)$ is the consumption share assigned to the worker upon hiring in period $\tau$ and $c(t)$ the consumption of the representative entrepreneur in the current period $t \geq \tau$. Notice that i) the wage of each worker moves together with entrepreneurial consumption during the life of a contract, and ii) the cross-sectional heterogeneity in wages is completely captured by differences in consumption shares. Solving for equilibrium requires keeping track of the shares promised to workers, but I will show that keeping track of the total extent of these promises is sufficient, instead of the entire cross-sectional distribution. Because of this, the payoff relevant state-space boils down to just two state variables: total employment and an employment weighted average of $a$ 's assigned to workers. Together with employment, this second variable is a sufficient statistic for keeping track of the total wage costs the entrepreneurial sector has committed to.

To show how the conditions of Proposition 2.2 can be expressed using these state variables, this section specializes to log-utility. Appendix B shows how to handle other CRRA utility functions, as well as heterogeneity in preferences between workers and entrepreneurs.

Integrating over cohorts of workers, denote total employment by $m(t):=\int_{-\infty}^{t} n(\tau, t) d \tau$. The law of motion for $m(t)$ is

$$
\dot{m}(t)=-\delta m(t)+\mu(\theta(t))(1-m(t)) .
$$

Employment decreases due to separation shocks at rate $\delta m(t)$ and increases via hiring at rate $\mu(\theta(t))(1-m(t))$.

Integrating over cohorts, denote the employment weighted average of assigned consumption shares in the workforce as $\Phi(t):=\frac{1}{m(t)} \int_{-\infty}^{t} n(\tau, t) a(\tau) d \tau$. The law of motion for $\Phi(t)$ is

$$
\dot{\Phi}(t)=\frac{\mu(\theta(t))(1-m(t))}{m(t)}[a(t)-\Phi(t)]
$$

The average consumption share of workers increases when new hires get an above-average consumption share $(a(t)>\Phi(t))$, and the impact of the increase depends on the measure of new hires relative to total workforce.

To express the equilibrium conditions in Proposition 2.2 using these two state variables, I define

\footnotetext{
${ }^{24}$ Or promised values.
} 
two auxiliary jump-variables:

$$
\begin{aligned}
& X(t):=\int_{0}^{\infty} e^{-(\rho+\delta) s}\left[\ln c(t+s)+\delta V^{u}(t+s)\right] d s-V^{u}(t), \\
& Y(t):=\int_{0}^{\infty} e^{-(\rho+\delta) s} \frac{z}{c(t+s)} d s .
\end{aligned}
$$

To see why these two seemingly arbitrary variables are useful here, notice that with log-utility, the $F(t)$ and $V(t)-V^{u}(t)$ appearing in Proposition 2.2 satisfy

$$
F(t)=\int_{0}^{\infty} e^{-(\rho+\delta) s} \frac{c(t)}{c(t+s)}[z-a(t) c(t+s)] d s=c(t)\left[Y(t)-\frac{a(t)}{\rho+\delta}\right]
$$

and

$$
V(t)-V^{u}(t)=\int_{0}^{\infty} e^{-(\rho+\delta) s}\left[\ln (a(t) c(t+s))+\delta V^{u}(t+s)\right] d s-V^{u}(t)=\frac{\ln a(t)}{\rho+\delta}+X(t) .
$$

Here $Y(t)$ is a measure of the present discounted value of output in a job, once divided by the current marginal utility of consumption. To get to the present value of profits $F(t)$, one needs to subtract the present value of wages, which simplifies due to the contract form. The utility gain to a worker from a new job, $V(t)-V^{u}(t)$, can be divided into two parts. The part captured by $X(t)$ is the gain to the worker if he were assigned consumption share one i.e. consumed the same as the entrepreneur during employment. This value must then be adjusted for the consumption share actually assigned to the worker. With log-preferences and the multiplicative form of the contract, this adjustment amounts to an additive correction term 25

With this, conditions 2.-4 in Proposition 2.2 can be written simply as

$$
\begin{aligned}
\frac{1-\alpha}{Y(t)-\frac{a(t)}{\rho+\delta}} & =\frac{\alpha}{a(t)\left[\frac{\ln a(t)}{\rho+\delta}+X(t)\right]}, \\
\kappa & =q(\theta(t)) c(t)\left[Y(t)-\frac{a(t)}{\rho+\delta}\right], \\
c(t) & =\frac{m(t) z-\kappa \theta(t)(1-m(t))}{1+m(t) \Phi(t)} .
\end{aligned}
$$

The variables $X(t), Y(t)$ satisfy the laws of motion 26

$$
\begin{gathered}
(\rho+\delta) X(t)=\ln c(t)-\ln b-\mu(\theta(t))\left[\frac{\ln a(t)}{\rho+\delta}+X(t)\right]+\dot{X}(t), \\
(\rho+\delta) Y(t)=\frac{z}{c(t)}+\dot{Y}(t) .
\end{gathered}
$$

\footnotetext{
${ }^{25}$ The key is to avoid having to keep track of the promised values corresponding to all cohorts of workers. Here I find a way to break down these values to two parts. One part is constant during the life of a contract, but varies across cohorts in a way which can be kept track of conveniently (such as $a(t)$ ). The other changes during the life of a contract, but is common to all cohorts (such as $X(t), Y(t)$ ).
} 
I can now represent the equilibrium as a homogenous system of differential equations in predetermined states $m(t), \Phi(t)$, and jump-states $X(t), Y(t)$ given by the dynamic equations (10), (11), (15) and (16) along with the static equations (12)-(14) determining $a, c, \theta$. Since the economy is stationary, I look for a solution converging to a steady-state.

Lemma 3.1. 1. The system (10)-(16) has a unique steady-state.

2. In the neighborhood of the steady-state, equations (12)-(14) implicitly define continuously differentiable functions $\tilde{a}(X, Y), \tilde{c}(m, \Phi, X, Y), \tilde{\theta}(m, \Phi, X, Y)$.

3. The system (10) -(16) has eigenvalues $\lambda_{1} \ldots \lambda_{4}$ s.t. $\lambda_{1}<-\delta<\lambda_{2}<0<\lambda_{3}=\rho<\rho+\delta<\lambda_{4}$ if $\frac{z}{\kappa(1-\alpha)}>\frac{\mu(\theta)+\rho+\delta}{\mu(\theta)+\rho+2 \delta} \frac{\rho+2 \delta}{\mu(\theta)}$.

The sufficient condition for the eigenvalues 27 holds for example if $\alpha \geq \frac{1}{2}$ or $\frac{b}{z} \geq \frac{1}{2}$. This implies a uniqueness result:

Proposition 3.1. Unique Equilibrium Path Given initial values $(m, \Phi)$ close enough to the steady-state and parameters satisfying the condition in Lemma 3.1, generically there is a unique equilibrium path converging to the steady-state.

\subsection{The Slow Dynamics of Wage Commitments and Their Impact on Employ- ment}

The previous section showed that the equilibrium has a representation as a small system of differential equations in two predetermined state variables: employment and a measure of wage commitments made by employers to the existing workforce. The fact that wage commitments are part of the state is an interesting dynamic feature absent from the Mortensen-Pissarides model.

How does $\Phi$ affect employment dynamics? The variable characterizes the extent of the entrepreneur's wage costs, hence affecting entrepreneurial consumption (equation (14)). Suppose employment is at steady-state, but these wage commitments are above their steady-state level. To reach the steady-state, the entrepreneurial sector will reduce their level over time as it hires new workers to replace separating ones. During the adjustment period entrepreneurial consumption is rising, which means that the interest rate must be above its steady-state value. A high interest rate makes investment into vacancy creation less profitable, reducing hiring and causing unemployment to rise. The speed of these adjustments depends both on the rate of turnover in the workforce, as well as the optimality conditions on hiring (determining $a$ ). Adjusting the consumption share of new hires too quickly can have adverse effects, because it implies that workers hired in the beginning of the transition receive lower contract values $(V)$ than those hired later on, when entrepreneurial consumption is higher. To see the quantitative impact of these effects, I calibrate the model.

\footnotetext{
${ }^{26}$ We have $X(t)=\Delta t\left[u(c(t))+\delta V^{u}(t)\right]+e^{-(\rho+\delta) \Delta t}\left[X(t+\Delta t)+V^{u}(t+\Delta t)\right]-V^{u}(t) \approx \Delta t\left[u(c(t))+\delta V^{u}(t)\right]+$ $X(t)-(\rho+\delta) \Delta t\left[X(t)+V^{u}(t)\right]+\Delta t\left[\dot{X}(t)+\dot{V}^{u}(t)\right]$, which implies $(\rho+\delta) X(t)=u(c(t))-\rho V^{u}(t)+\dot{V}^{u}(t)+\dot{X}(t)$. Combining this with the equation for $V^{u}(t)$ implies the equation in the text.

${ }^{27}$ The constraints have to do with separating the two negative roots. A nicer condition can probably still be found.
} 
Calibration The calibration strategy follows Shimer (2005a), though the thrust of the results is not particularly sensitive to reasonable changes in parameters. Time units are chosen to be months. The monthly discount rate is set to $\rho=0.05 / 12=0.004$. Productivity $z$ is normalized to one. To be consistent with the empirical separation and job-finding rates set $\delta=0.035$ and calibrate such that in steady-state $\mu(\theta)=0.46$. The matching function elasticity is set to $\alpha=0.72$ also following Shimer (2005a). The units of vacancies are chosen such that in steady-state $\theta=1$ and to match the job-finding rate, $k=0.46$. The vacancy cost is used as a free parameter to make sure the zero profit condition: $\kappa=q(1) \frac{z-w}{\rho+\delta}$ holds for any level of $w$. The quantitative exercises consider alternative configurations of $b, \gamma$.

The dynamics of the model are characterized by a dichotomy in speeds of convergence. Employment dynamics are strongly affected by the faster eigenvalue of the system, which has a half life of approximately 1.5 months in the calibrated model (independent of $b, \gamma$ ). This is similar to the employment dynamics of the standard Mortensen-Pissarides model. The second eigenvalue can be associated with the dynamics of wage commitments $\Phi$. These dynamics are clearly beyond business cycle frequency, with the half-life varying between $50-7000$ months, as $b$ is varied between $0.4-0.9$ and $\gamma$ between $0-528$

Figure 1 illustrates the impact of wage commitments on employment in the calibrated model. Suppose that initially $\Phi$ is $10 \%$ above steady-state 29 The figure shows the high interest rate associated with rising entrepreneurial consumption, the resulting low vacancy-unemployment ratio and rise in unemployment. Over time all variables return to their steady-state levels. On the other hand, with linear preferences the adjustments in consumption have no impact on the interest rate nor the profitability of vacancy-creation. Unemployment is hence unaffected.

Two quantitative observations deserve mention: i) The unemployment dynamics induced by the consumption share variable are slow. They are also suggestive of a hysteresis effect in the sense that a shock causing an imbalance in the consumption share variable can lead to a persisting deviation of employment from its steady-state level. ii) In terms of magnitudes, the effects of $\Phi$ turn out to be small in the calibrated model. These interesting dynamics hence become overshadowed in magnitude.

\section{The Quantitative Impact of Incomplete Markets}

This section uses the fully dynamic model with aggregate shocks to evaluate the quantitative importance of incomplete markets for business cycles in the labor market. The solution method applies the same approach for reducing the state space of the problem as the last section. The details of the method and simulations are discussed in Appendix D.

I begin by presenting the main quantitative results, and then proceed to explore i) what are the roles of market structure versus changing preferences for these results, and ii) what is the impact of

\footnotetext{
${ }^{28}$ For the faster root higher $b$ generally speeds up convergence while higher $\gamma$ slows it down. For the slower root higher $b$ generally slows convergence while higher $\gamma$ speeds it up.

${ }^{29}$ With $\gamma=4$, a two percent decrease in productivity leads to roughly 0.3 percent decrease in the steady-state employment level and a ten percent increase in the steady-state level of $\Phi$.
} 
W
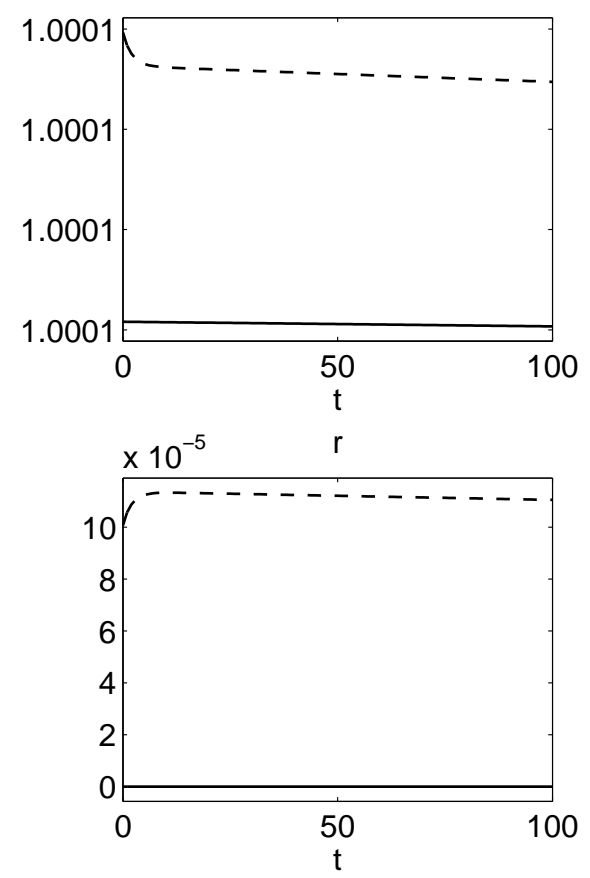

$\theta$

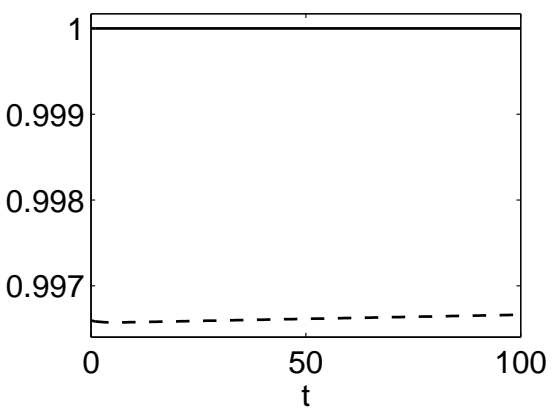

unemployment

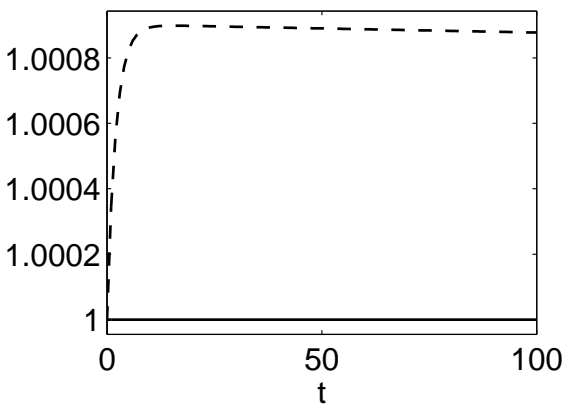

Figure 1: Effect of wage commitments on employment

Notes: The figure shows the adjustment path toward steady-state when initially $\Phi$ is ten percent above steady-state and employment is at steady-state value, for linear utility (solid line) and risk aversion $\gamma=4$ (dashed line). All variables are plotted relative to steady-state, apart from the interest rate which is reported as percentage point deviation from steady-state. $b=0.8$. The wage refers to the aggregate wage i.e. the cross sectional average.

preference heterogeneity for the results. I illustrate the model's implications for individual wages, and finally, discuss the implications of relaxing the assumption that parties can commit to contracts.

\subsection{Amplification in Unemployment Fluctuations}

Figure 2 shows the quantitative impact of incomplete markets on the cyclical volatility of the vacancy-unemployment ratio and wages, for alternative values of $b, \gamma$. I examine two alternative measures of volatility: standard deviations relative to labor productivity and elasticities with respect to labor productivity. The second measure incorporates a correction for the low correlation of the vacancy-unemployment ratio and wages with productivity in the data $(0.4$ and 0.6 , respectively), compared to the perfect correlation in the model (which has only one shock) 30

\footnotetext{
${ }^{30}$ The data for productivity and wages are taken from the website of the Bureau of Labor Statistics, the Major Sector Productivity and Costs section. The measure of labor productivity used is quarterly real output per worker for the non-farm business sector for 1951 - 2005. The measure of wages is quarterly real compensation per worker for the non-farm business sector, which I construct using the quarterly compensation and employment data reported. As the model has no hours choice, what I call the wage is per worker compensation. The BLS reports a current dollar compensation index, which I deflate by the CPI for all urban consumers and divide by the employment series. The
} 

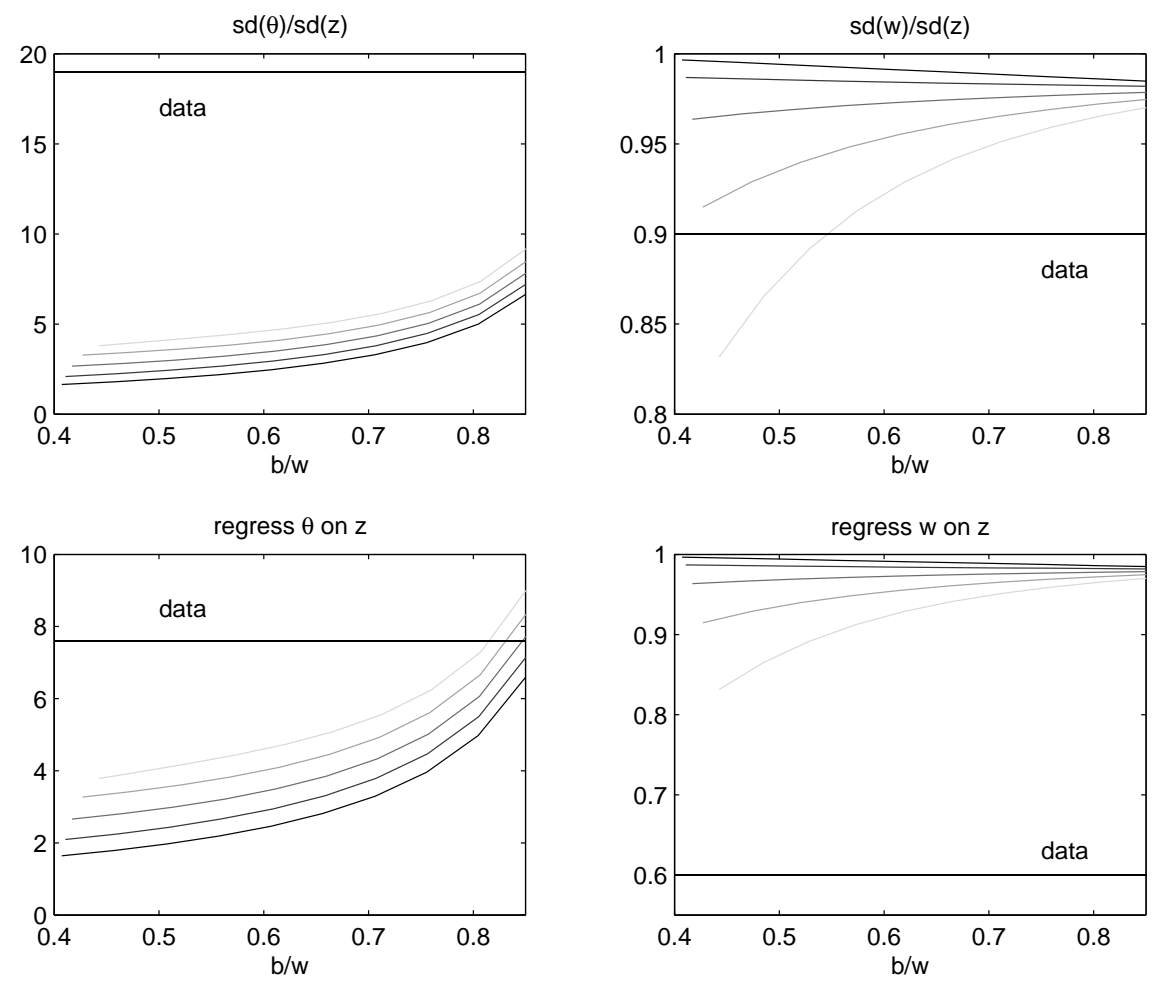

Figure 2: Volatility of the labor market under incomplete asset markets

Notes: The figure plots volatility measures based on simulations of the incomplete markets model, comparing to empirical levels. See Appendix $\mathrm{D}$ for details on the simulations. Risk aversion levels $\gamma=0,1,2,3,4$, grey color fades out with higher $\gamma$. The wage refers to the aggregate wage i.e. the cross sectional average. As $b, \gamma$ vary, the steady-state is re-calibrated to match observed unemployment.

The figure presents the results as sensitivities to $b$, the consumption of the unemployed. This is done because on the one hand, the results are known to be sensitive to the value of $b$ used 31 and on the other, the literature presents differing views on the appropriate calibration of this parameter. Shimer (2005a) calibrates targeting an unemployment benefit replacement ratio of 0.4 , while Hagedorn and Manovskii (2006) argue for a much higher value of 0.95 to take into account other factors affecting consumption. Costain and Reiter (2003) and Hall and Milgrom (2007) proceed to argue against such a high value, which suggests that workers are almost indifferent about being unemployed. The empirical evidence on how much consumption falls upon unemployment is as follows: Aguiar and Hurst (2005) report that food consumption drops by 5\%, Gruber (1997) and Stephens (2001) report food expenditures dropping by $7-10 \%$, Browning and Crossley (2001)

measure of vacancies is the Conference Board's help-wanted advertising index and the unemployment data are based on the Current Population Survey. All data are logged and $H P\left(10^{5}\right)$-filtered. This filter is chosen to be consistent with the literature examining the volatility puzzle.

${ }^{31}$ When $b$ is high and workers relatively indifferent about being unemployed, productivity variation of a given magnitude leads to larger variation in employment (Hagedorn and Manovskii 2006). The surplus from matching is small, so productivity shocks of a given size lead to large percentage variation in hiring. 
report a broader set of consumption expenditures dropping by $14 \%$.

The point of reference in the figure is the darkest line, corresponding to linear preferences. In this case access to asset markets is irrelevant and the model reproduces the employment dynamics of the standard Mortensen-Pissarides model, including the low volatility of the vacancy-unemployment ratio relative to data. As the workers' willingness to substitute consumption falls, wage volatility falls and the volatility of the vacancy-unemployment ratio rises, bringing the model closer to data on both counts. The measure of volatility examined affects how close to the data the incomplete markets mechanism can bring the model, by affecting the size of the gap between model and data. The results show that while the incomplete markets environment leads to a significant increase in the cyclical volatility of unemployment, the changes remain relatively moderate in magnitude when compared to the large difference between model and data. Given the extreme form of market incompleteness in the model, the results suggest an upper bound on how far incomplete markets alone can go in explaining the unemployment volatility puzzle.

The changes in dynamics due to incomplete markets turn out to be closely related to the changes in the steady-state of the economy discussed in Section 3.1. To see how much predictive power the steady-state has about outcomes in the dynamic model, Figure 3 plots the steady-state elasticities of the vacancy-unemployment ratio and wages to productivity (based on equation (9)), for the calibrated model. Comparing outcomes to Figure 2 reveals a striking similarity - the steadystate elasticities are informative even of the magnitudes of responses in the dynamic model. This suggests that the discussion in section 3.1 on the incomplete markets mechanism captures the most important quantitative changes in dynamics.
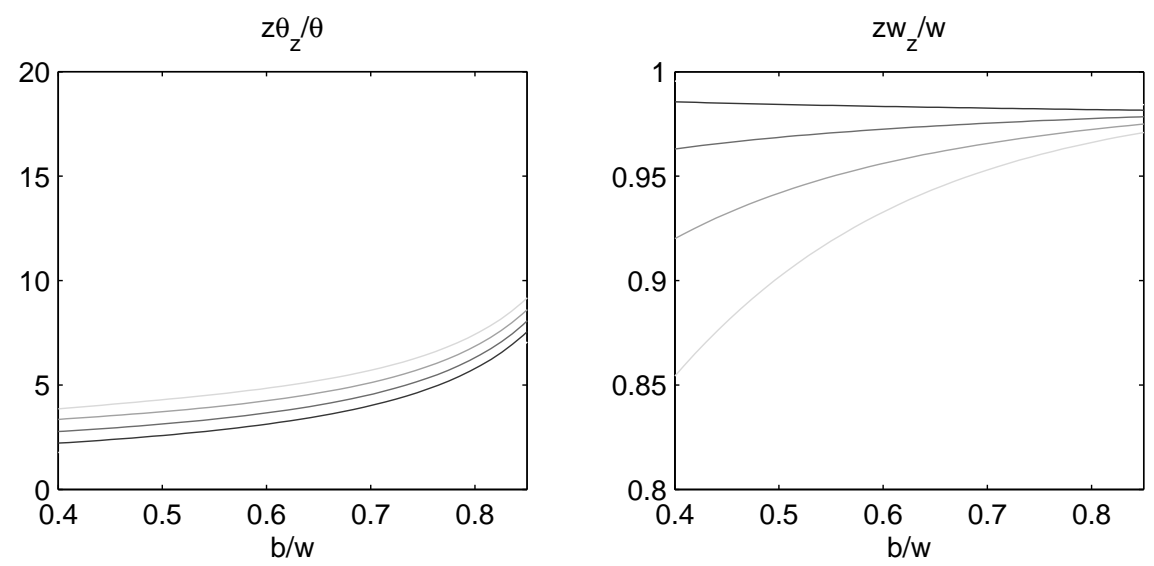

Figure 3: Steady-state elasticities with respect to permanent productivity changes

Notes: The figure plots elasticities of the steady-state vacancy-unemployment ratio and wage with respect to changes in steady-state productivity. Risk aversion levels $\gamma=0,1,2,3,4$, grey color fades out with higher $\gamma$. As $b, \gamma$ vary, the steady-state is re-calibrated to match observed unemployment.

Note that to keep the unemployment level fixed when comparing different values of $\gamma$ in Figures 2 and 3, the calibration procedure adjusts the vacancy-cost 32 To see how the figure would look with

\footnotetext{
${ }^{32}$ The vacancy cost increases in $\gamma$ to keep unemployment from falling, and falls in $b$ to keep unemployment from
} 
$\kappa$ fixed, see Appendix C]

\subsection{Role of Market Structure versus Preferences}

To what extent are the changes in dynamics due simply to changing preferences? To understand the impact of changing market structure alone, this section compares outcomes under incomplete markets to those under complete markets, holding preferences fixed. For this comparison, I consider a variant of the Mortensen-Pissarides model with non-linear preferences where workers can trade in claims spanning both aggregate and idiosyncratic risk, allowing them to insure away their idiosyncratic unemployment risk. This case in not new to the literature 33 and Appendix $\mathrm{F}$ discusses how to solve it.

Returning to examine the steady-state for a prediction about how this case differs from the linear utility model reveals that the two have the same steady-state. When workers can insure their consumption against unemployment spells, their job search behavior is based solely on maximizing the present value of income. In the absence of aggregate shocks their behavior is identical to that of agents with linear preferences. If the steady-state gives accurate predictions about the dynamics of the model, this suggests that changes in preferences will not affect outcomes significantly when workers face complete markets.

To see how the dynamics are affected, Figure 4 compares impulse responses to a labor productivity shock in three cases: i) when agents have linear preferences, ii) when agents have CRRA preferences with $\gamma=4$ and workers face complete markets, and iii) when agents have CRRA preferences with $\gamma=4$ and workers face incomplete markets. To generate the figure productivity $z$ starts one percent above steady-state and the other state variables $m, \Phi$ at steady-state. As $z$ is mean reverting, the conditional expectation $E[z(t) \mid z(0)]$ converges to steady-state over time. The figure plots the time paths of conditional expectations of starting wages, market tightness, interest rate and unemployment in response to this.

To understand the responses, consider first what happens to vacancy creation upon a productivity increase. Vacancy creation will typically increase with increased productivity, but in addition entrepreneurs may find it optimal to offer better contracts to workers (with a higher utility value of wages) to attract more of them. Both responses will work toward driving the profits from vacancy creation back to zero. How much the entrepreneurs adjust wages up depends on their beliefs about how such changes will affect their costs of hiring workers through attracting more applicants per vacancy. The beliefs depend on how workers value wages, and hence both their preferences and the markets they face. When agents have non-linear preferences, the dynamic responses to shocks will be affected also by their preference for consumption smoothing, reflected in interest rates.

The figure shows the productivity increase translate into an increase both in market tightness and the starting wage level, with the increased market tightness causing unemployment to fall. When workers have access to complete asset markets, concavity in preferences changes the dynamics of unemployment quantitatively little relative to the linear case. The interest rate responds to the

rising.

${ }^{33}$ See e.g. Andolfatto (1996) and Merz (1995). 

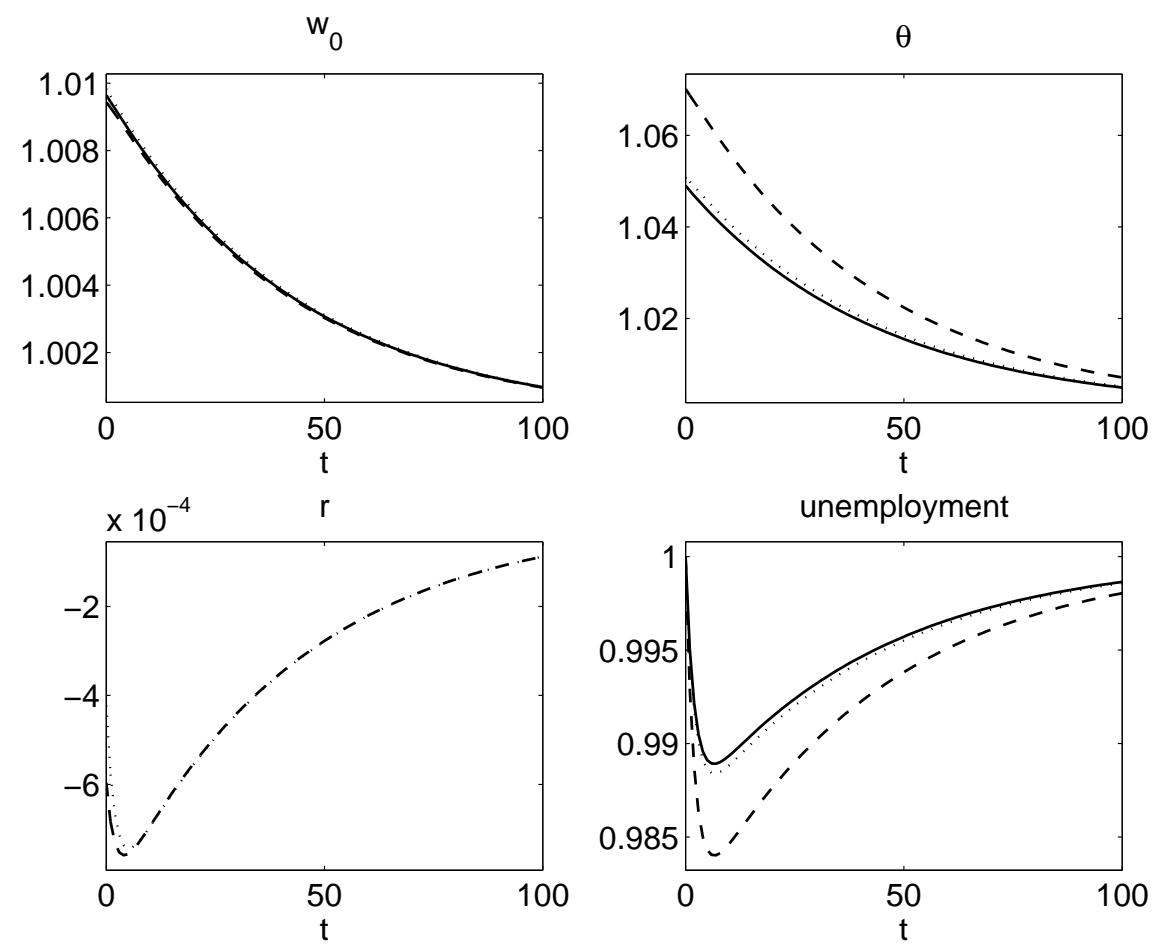

Figure 4: Impulse responses in three environments

Notes: The figure plots impulse responses of endogenous model variables to a one percent positive productivity shock. See Appendix $\mathrm{D}$ for details. All variables are plotted relative to steady-state, apart from the interest rate which is reported as percentage point deviation from steady-state. Three cases: i) the incomplete markets model with linear preferences (solid line), ii) the complete markets model with $\gamma=4$ (dotted line), and iii) the incomplete markets model with $\gamma=4$ (dashed line). $b=0.8$. Under complete markets, the plotted wages are based on continual re-bargaining. Under incomplete markets, the wage refers to the starting wage in a new job. Time is in months.

positive productivity shock by falling, adding to the profitability of vacancy-creation. This leads to amplification in the responses of both market tightness and wage to the shock, but the changes are small in magnitude 34

When workers are unable to smooth consumption through asset markets, concavity in preferences instead dampens the wage response, while the response of the vacancy-unemployment ratio is amplified more strongly. This outcome can be viewed as a combination of two effects: i) As in the complete markets case, a change in preferences changes the transitional dynamics following a productivity shock, because it affects the degree of consumption smoothing preferred. ii) Under incomplete markets, a change in preferences affects also the more long-term response of variables to a persisting productivity shock. This second effect reflects the changes in the steady-state of the economy. The incomplete markets outcome in Figure 4 combines these two effects which work in the same direction for the vacancy-unemployment ratio and in opposite directions for the wage.

\footnotetext{
${ }^{34}$ Moreover, they can be ambiguous in direction. Increasing the persistence of the shock reverses the direction of the effect, causing the interest rate to rise and dampening the responses of both variables to the shock.
} 
Figure 5 presents simulated moments for a range of values of $b, \gamma$, confirming that the second effect appears to dominate quantitatively 35
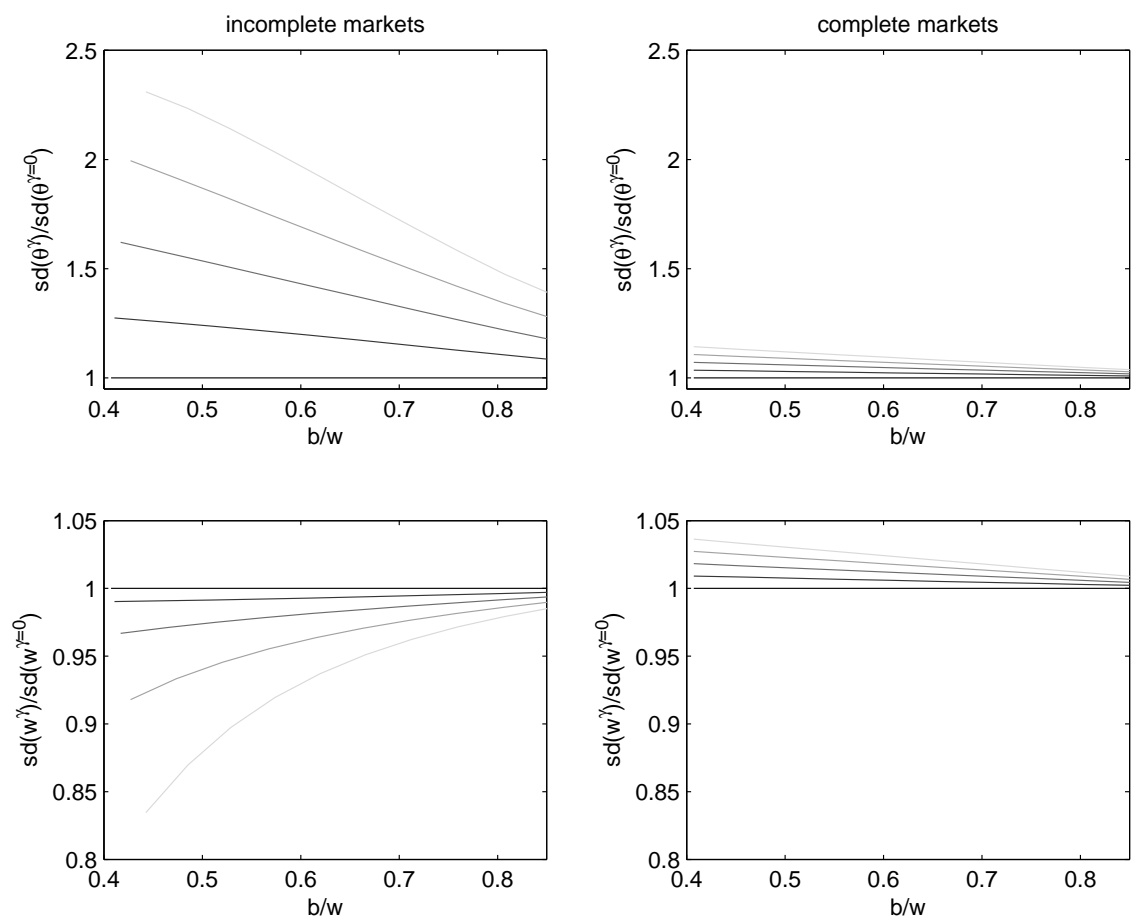

Figure 5: The effect of increasing $\gamma$ on volatility under complete vs. incomplete markets

Notes: The figure plots volatility measures based on simulations of the incomplete and complete markets models. See Appendix $\mathrm{D}$ for details on the simulations. Risk aversion levels $\gamma=0,1,2,3,4$, grey color fades out with higher $\gamma$. In the complete markets case the wages are based on continual re-bargaining. In both cases the wage refers to the aggregate wage i.e. the cross sectional average. As $b, \gamma$ vary, the steady-state is re-calibrated to match observed unemployment.

\subsection{Heterogeneity in Willingness to Substitute Consumption}

A tradition in economics dating back to Knight (1921) argues that workers are more risk averse than entrepreneurs, perhaps through selection (Kihlstrom and Laffont 1979). The model is straightforward to extend to allow for such differences, and I provide the details in Appendix B. I find that the changes in unemployment dynamics resulting from changing $\gamma$ are effectively due to changes in the workers' risk aversion, with entrepreneurial risk aversion making only little difference. This is consistent with the prediction based on the steady-state, which is independent of the latter. (see Appendix C). Preferences matter for the steady-state only because workers cannot use asset

\footnotetext{
${ }^{35}$ It may appear puzzling that small changes in wages correspond to large changes in market tightness. This has to do with the fact that entrepreneurs make only a small operating profit from each match in this model, so small adjustments to the present value of wages can have percentage-wise large effects on the present value of profits and hence vacancy-creation.
} 
markets to smooth their consumption, and hence their search behavior is guided by maximizing the present value of utility rather than that of income. The entrepreneurs face no such constraints, and simply maximize the present value on income.

At the same time, entrepreneurial risk aversion has a clear impact on aggregate wages. It determines how much consumption smoothing entrepreneurs provide workers through the wage contract and hence the cyclicality of within-contract wages. This in turn contributes to the cyclicality of the aggregate (or average) wage. Figure 6 illustrates the contract wages that the model generates for a 100 month realization of the productivity process. Panel i) shows wages for the benchmark case with equal $\gamma$. In this case entrepreneurs and workers fully share aggregate fluctuations, making contract wages quite cyclical. The black line shows the level of starting wages over time, and the gray lines trace out individual contract wages for the average duration of a job, 30 months. Contract wages comove closely with productivity, and even though aggregate conditions at the time of hiring have a persisting effect on the worker's wage during the job, the effect is quantitatively small. Hence the cross-sectional wage dispersion arising from such differences is also small.
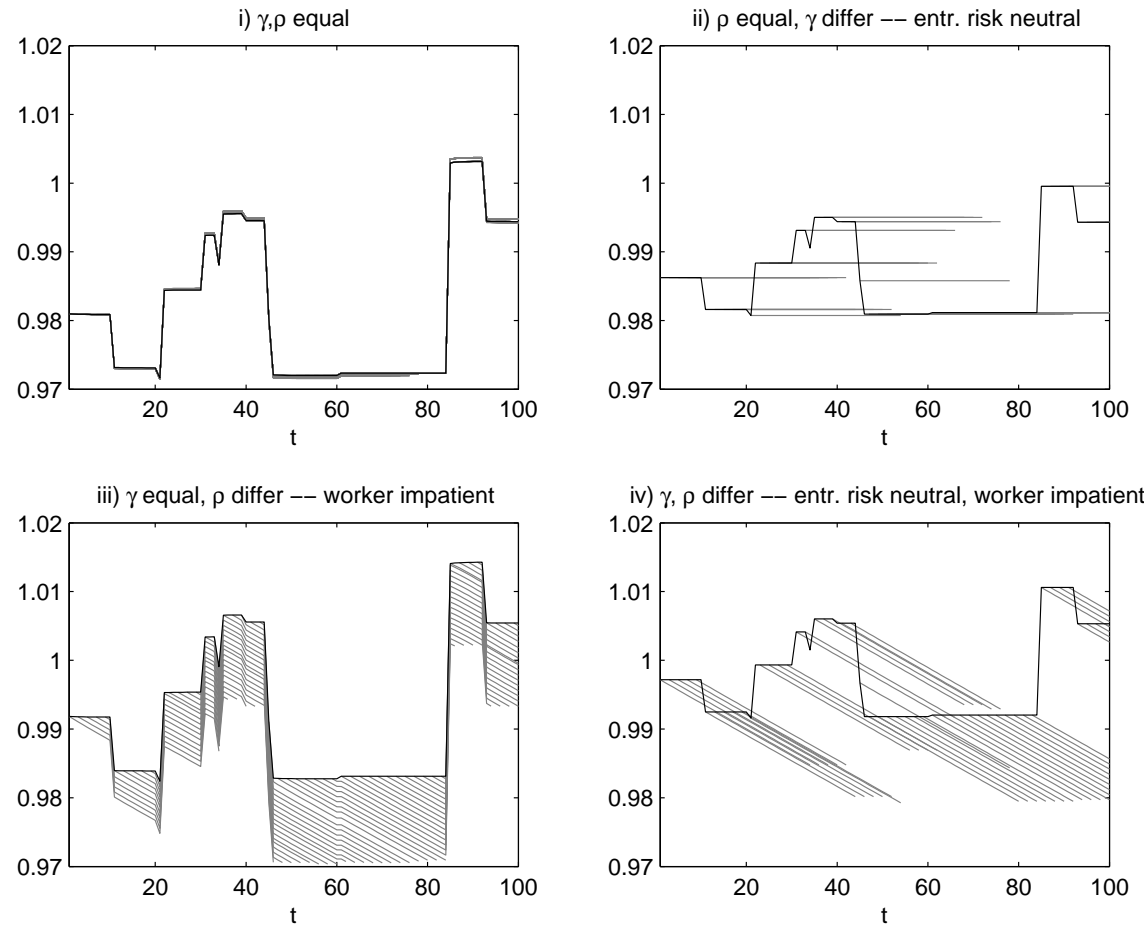

Figure 6: Example of contract wages

Notes: The figure plots a simulation path of contract wages. The black line traces out the level of starting wages at any point in time and the grey lines trace out how the contract wage evolve after signing, for the average duration of a job i.e. $\frac{1}{\delta} \approx 30$ months. Four example cases: i) the worker and entrepreneur have identical preferences with $\gamma=\hat{\gamma}=1$ and $\rho=\hat{\rho}=0.05 / 12$, ii) both parties have the same discount rate as in i), but entrepreneurs are risk neutral: $\gamma=0, \hat{\gamma}=1$, iii) the parties have the same risk aversion $\gamma=\hat{\gamma}=1$, but workers are more impatient $\hat{\rho}=0.055 / 12>\rho=0.05 / 12$, and iv) heterogeneity in both: $\gamma=0, \hat{\gamma}=1$, and $\hat{\rho}=0.055 / 12>\rho=0.05 / 12$. 
Comparing panels i) and ii) shows how entrepreneurial risk aversion affects contract wages. The more flexible entrepreneurs are, the more wage smoothing they provide through acyclical contract wages. When entrepreneurs have linear preferences, as in panel ii), contract wages are constant over time. Here the model is clearly consistent with the empirical finding that starting wages are more cyclical than wages in ongoing jobs (Barlevy 2001, Bils 1985, Shin 1994, Solon, Barsky, and Parker 1994), as starting wages are clearly procyclical. Relative to the previous case, the figure indicates both increased wage dispersion in the cross-section and reduced cyclicality of the aggregate wage. In fact, in this limiting case the aggregate wage becomes less cyclical than the data 36 but unless one assumes that entrepreneurs are nearly risk neutral, the model will tend to produce wages that are more cyclical than data.

How can these differing wage paths be consistent with similar behavior of unemployment? What matters for unemployment is the cyclicality of the present value of wages that entrepreneurs promise newly hired workers, because this is what affects the costs of hiring. Depending on entrepreneurial preferences, similar present values will be delivered via different contract forms, with differing implications for how wages evolve over time. This means that observations about wage cyclicality may not be very informative about unemployment, unless one can either examine the present values directly, or is willing to take a stand on the preferences of workers versus entrepreneurs 37 In sections 4.1 and 4.2 I examined how $\gamma$ changes the response of the starting wage to shocks. Underlying these exercises is the idea that when workers and entrepreneurs have identical preferences, changes in how the starting wage responds to shocks are indicative of changes in how the present value of wages responds. Similarly I examined changes in the cyclicality of aggregate wages, as these changes are associated with changes in the cyclicality of starting wages. With data on the present values, one could compare outcomes to those directly, but because deriving such estimates is beyond the scope of this paper, I have instead proceeded with this alternative approach, taking the view that the risk aversion level of entrepreneurs remains non-trivial.

\subsection{Impatient Workers}

One reason why wealth is concentrated in the hands of entrepreneurs could be that they are more patient than workers. The model is straightforward to extend to allow for differences in discount rates between the two groups, and I provide the details for the extension in Appendix B. Will such differences have a significant impact on the amplification properties discussed? My simulation results indicate that doubling the discount rate of workers does not substantially affect the conclusions on unemployment volatility. Appendix $\mathbb{C}$ gives the appropriate steady-state equation which can be used to gauge the impact.

Panels iii) and iv) in Figure [6 illustrate that when workers are less patient than entrepreneurs, contract wages drift down over time, creating additional wage dispersion in the cross-section. This prediction of front-loading in wage contracts is a natural outcome of optimal contracting when

\footnotetext{
${ }^{36}$ See Rudanko (2008).

${ }^{37}$ This is immediate in the standard Mortensen-Pissarides model, where linear preferences leave the contract form indetermined, but holds also here as a quantitative result. The observation supports recent attempts to look for alternative ways of verifying the wage rigidity hypothesis of Hall (2005) beyond examining the cyclicality of the aggregate wage series (Haefke, van Rens, and Sonntag 2007, Kudlyak 2007, Pissarides 2007)
} 
parties have differing time discount rates.

\subsection{Role of Commitment in Contracting}

I have assumed that both workers and entrepreneurs can fully commit to long-term wage contracts. As the outside options of the contracting parties evolve over the cycle, at some point either party may potentially prefer leaving the existing contract to pursue their outside option. Whether the commitment assumption actually does bind depends on the type of contract in place. When workers and entrepreneurs have identical preferences, contract wages rise in booms, reducing the incentive of the worker to quit the current job, and fall in downturns, reducing the incentive of the entrepreneur to fire the worker. Wage differences between workers hired at different times are small, suggesting that the commitment assumption may be innocuous. To evaluate this hypothesis, I checked during the simulations conducted whether the assumption was binding, and discovered that it was indeed not.

When the preferences of workers and entrepreneurs differ, the commitment assumption becomes more restrictive, however. Rudanko (2008) explores how outcomes change when parties are assumed to have limited commitment in contracting, focusing on a setting where the commitment assumption is particularly restrictive - when workers are risk averse and entrepreneurs risk neutral, and contract wages hence fully insulated from changes in aggregate conditions taking place after the contracting period (case ii) in Figure 6). In that setting leaving the prevailing contract will at times dominate staying 38 The paper finds that relaxing the commitment assumption increases the cyclicality of both aggregate wages and unemployment. With respect to the unemployment volatility puzzle, the quantitative impact is found to be relatively small because of the large gap between model and data, however.

\section{$5 \quad$ Related Literature}

Several recent papers examine the effects of incomplete markets on business cycles in the MortensenPissarides model: Bils, Chang, and Kim (2007), Costain and Reiter (2005), Krusell, Mukoyama, and Sahin (2007), Nakajima (2008) and Shao and Silos (2007). These papers provide a useful complement by adopting a different approach to modeling incomplete markets - an Aiyagari-style approach with precautionary saving. Relative to these papers, the current paper has the advantage of being significantly easier to solve, offering transparency and a simple illustration of the key mechanism at work. The solution methods applied in the other papers are significantly more computationally heavy, because not only does one need to take into account the wealth distribution as a state variable, but the problem becomes particularly challenging because individual wages in principle depend on individual wealth in a non-trivial way. While the models hence capture potentially interesting wealth effects which are not present here, the mechanism of wage-setting has to be simple for tractability reasons, and several of the papers take shortcuts on this dimension. The present paper, on the other hand, steps beyond the norm to develop the long-term contracting

\footnotetext{
${ }^{38} \mathrm{~A}$ worker hired in a downturn with a low (constant) wage may prefer to quit in a boom. An employer may prefer to fire a worker hired during a boom when a recession hits, because of high wage costs.
} 
aspect of wages. The papers also face the challenge of producing empirically consistent wealth distributions, where the unemployed do not hold significant amounts of wealth. In terms of results, the papers are consistent in finding that market incompleteness amplifies cyclical fluctuations in unemployment, but that the effect is quantitatively not large enough to overturn the volatility puzzle.

Several authors have proposed alternative wage-setting mechanisms for the Mortensen-Pissarides model, exploring potential sources of amplification. Hall and Milgrom (2007) change the threat point in the bargaining problem determining wages. Gertler and Trigari (2006) impose Calvo-style staggered wage bargaining into the model. A set of papers enrich the problem with search on-thejob (e.g. Menzio and Shi (2008), Nagypál (2006)) or informational asymmetries (e.g. Brügemann and Moscarini (2007), Kennan (2007)). Closest in spirit to this paper, Rudanko (2008) explores long-term wage contracting under limited commitment. As here, the focus is on long-term contracts based on an insurance motive, but the problem simplifies significantly because capitalists are assumed to have linear preferences. Embedding interesting contracting problems into a general equilibrium macro-model is challenging, but as the present paper illustrates, it does not necessarily need to lead to significant limitations for quantitative analysis.

\section{Conclusions}

This paper showed that when workers cannot smooth consumption privately, cyclical fluctuations in unemployment are amplified compared to a complete markets environment. This is due to changes in how workers value wages, when they cannot smooth their consumption across unemployment and employment spells. Because they benefit less from a high wage, their job search behavior is distorted toward lower wages, causing the equilibrium to shift toward lower wages as well. The distortion is larger in periods when high productivity bids up the wage level, and relaxes in periods of low productivity. Because the wage level responds less to changes in productivity in this environment, vacancy-creation and unemployment respond more.

The paper demonstrated this in a tractable model framework where risk-averse entrepreneurs post optimal dynamic long-term contracts to attract risk-averse workers. The equilibrium was shown to have a simple representation as a small system of differential equations, in two endogenous state variables: wage commitments and employment. While the key mechanism could be demonstrated simply by examining the steady-state of the economy, the model also allowed exploring transitional dynamics, as well as having flexibility for extensions - in addition to preference heterogeneity, one could easily incorporate for example capital or idiosyncratic risk in production 39 An interesting policy application of the model would be to examine the positive and welfare effects of cyclical labor market policies, such as counter-cyclical benefits. The welfare effects of such policies are not clear, because although they provide workers insurance, they may lead to increased volatility in

\footnotetext{
${ }^{39}$ In addition to aggregate risk, in reality entrepreneurs face significant idiosyncratic risks. How would they affect outcomes in the model? If the capitalists in the economy were able to diversify investments across production units, they would be able to insure their consumption against this risk, as well as the wages/consumption of their workers. While contract wages would be unaffected, the shocks would be important for guiding employment decisions, also affecting the wage level in new jobs. With a linear production technology, only the highest productivity units would be hiring.
} 
the labor market.

Finally, I have not addressed whether the equilibrium is efficient or not. Clearly it is not efficient from an unconstrained point of view because workers face a drop in consumption upon unemployment. Even if the social planner were constrained by technology not to redistribute to the unemployed, the employed workers' consumption still depends on the time of hiring, suggesting inefficiency. Whether one can define a notion of constrained efficiency such as to guarantee efficiency of equilibrium remains an open question.

\section{Appendix A Proofs}

\section{Proof of Lemma 2.1; Equilibrium Properties}

Lemma 2.1 is implied by the following Lemmas A.1. A.4.

First, assume an equilibrium exists. As discussed in the text, the choice of contract at any point $t$ solves the problem ( (P1) in the text. This problem separates into a) a problem of finding the structure of optimal wage contracts (P1.a) and b) a problem of finding the optimal level of wages given this structure (P1.b).

a) Form of Optimal Wage Contract: Given $\mathcal{F}_{t}, t \geq 0$, the processes $p(t+s), V^{u}(t+s)$, for all $s \geq 0$, and continuations $\mathcal{F}_{t+s}$, and a corresponding value $\bar{V}>V^{u}(t)$, choose $w^{i}(t, t+s)$, for all $s \geq 0$, and continuations $\mathcal{F}_{t+s}$, to

$$
\begin{aligned}
& \max E_{t} \int_{0}^{\infty} e^{-\delta s} p(t+s)\left[z(t+s)-w^{i}(t, t+s)\right] d s \\
& \text { s.t. } \bar{V} \leq E_{t} \int_{0}^{\infty} e^{-(\rho+\delta) s}\left[u\left(w^{i}(t, t+s)\right)+\delta V^{u}(t+s)\right] d s .
\end{aligned}
$$

Lemma A.1. With equilibrium prices, the wage contract problem (P1.a) has a unique solution with the property

$$
e^{-\rho s} \frac{u^{\prime}\left(w^{i}(t, t+s)\right)}{u^{\prime}\left(w^{i}(t, t)\right)}=\frac{p(t+s)}{p(t)}
$$

for all $t, s \geq 0$, and $\mathcal{F}_{t} \subset \mathcal{F}_{t+s}$.

Pf. This problem can be written as

$$
\begin{aligned}
& \min E_{t} \int_{0}^{\infty} e^{-\delta s} p(t+s) w^{i}(t, t+s) d s \\
& \text { or } \quad \max E_{t} \int_{0}^{\infty} e^{-(\rho+\delta) s} u\left(w^{i}(t, t+s)\right) d s \\
& \text { s.t. } \underline{V} \leq E_{t} \int_{0}^{\infty} e^{-(\rho+\delta) s} u\left(w^{i}(t, t+s)\right) d s \\
& \text { s.t. } E_{t} \int_{0}^{\infty} e^{-\delta s} p(t+s) w^{i}(t, t+s) d s \leq \underline{B}
\end{aligned}
$$

This is a standard problem where the FOC characterize a unique optimum.

b) Optimal Wage Level in Hiring: Optimal wage contracts equate marginal rates of substitution between different dates and states to the corresponding price ratio 40 Hence, once one knows the initial wage in a contract, future wages are pinned down as $w^{i}(t, t+s)=w^{i}(t, t)\left(e^{\rho s} \frac{p(t+s)}{p(t)}\right)^{-\frac{1}{\gamma}}$ according to prices. Using the shorthand $w^{i}(t, t+s)=w^{i}(t, t) f(t, t+s)$, we are left with the problem: Given $\mathcal{F}_{t}, t \geq 0$ and the processes

\footnotetext{
${ }^{40}$ Note that prices are weighted by probabilities in this notation.
} 
$p(t+s), V^{u}(t+s)$, for all $s \geq 0$, and continuations $\mathcal{F}_{t+s}$, choose $\theta^{i}(t), w^{i}(t, t)$ to solve

$$
\begin{array}{r}
\max -p(t) \kappa+q\left(\theta^{i}(t)\right) E_{t} \int_{0}^{\infty} e^{-\delta s} p(t+s)\left[z(t+s)-w^{i}(t, t) f(t, t+s)\right] d s \\
\text { s.t. } \rho V^{u}(t)=u(b)+\mu\left(\theta^{i}(t)\right)\left[E_{t} \int_{0}^{\infty} e^{-(\rho+\delta) s}\left[u\left(w^{i}(t, t) f(t, t+s)\right)+\delta V^{u}(t+s)\right] d s-V^{u}(t)\right] \\
+\eta\left[E_{t,+} V^{u}(t)-V^{u}(t)\right]+\frac{d}{d t} V^{u}(t) .
\end{array}
$$

Lemma A.2. For equilibrium $p(),. V^{u}($.$) , the wage level problem (P1.b) has a unique solution, characterized$ by

$$
\frac{1-\alpha}{F_{p}^{i}(t)}=\frac{\alpha u^{\prime}\left(w^{i}(t, t)\right)}{V^{i}(t)-V^{u}(t)}
$$

where

$$
\begin{aligned}
F_{p}^{i}(t) & :=E_{t} \int_{0}^{\infty} e^{-\delta s} \frac{p(t+s)}{p(t)}\left[z(t+s)-w^{i}(t, t+s)\right] d s, \\
V^{i}(t) & :=E_{t} \int_{0}^{\infty} e^{-(\rho+\delta) s}\left[u\left(w^{i}(t, t+s)\right)+\delta V^{u}(t+s)\right] d s .
\end{aligned}
$$

Pf. Note first that the processes for $p$ and $V^{u}$ are taken as given here. Moreover, I wish to examine equilibria with $V^{i}-V^{u}>0$, where $V^{i}$ is the value to a worker from signing a new contract $i 41$

Denote starting wages by $\hat{w}$ and define the net utility to a worker from a new contract as

$$
g(\hat{w}, t):=E_{t} \int_{0}^{\infty} e^{-(\rho+\delta) s}\left[u(\hat{w} f(t, t+s))+\delta V^{u}(t+s)\right] d s-V^{u}(t) .
$$

This function is strictly increasing in the wage, so if I define $\underline{w}$ such that $g(\underline{w}, t)=0$, then for any $\hat{w}>\underline{w}$, $g(\hat{w}, t)>0$. In particular, for equilibrium contracts $g\left(w^{i}(t, t), \bar{t}\right)=V^{i}(t)-V^{u}(t)>0$.

For any initial wage $\hat{w}>\underline{w}$, equation

$$
\rho V^{u}(t)=u(b)+\mu(\hat{\theta}) g(\hat{w}, t)+\eta\left[E_{t,+} V^{u}(t)-V^{u}(t)\right]+\frac{d}{d t} V^{u}(t)
$$

implicitly defines $\hat{\theta}$ as a function of $\hat{w}$. Substituting this into the maximand and differentiating w.r.t $\hat{w}$ we get:

$$
\bar{V}(t)^{-\frac{\alpha}{1-\alpha}} g(\hat{w}, t)^{\frac{\alpha}{1-\alpha}}\left[\frac{\alpha}{1-\alpha} \frac{g_{1}(\hat{w}, t)}{g(\hat{w}, t)} h(\hat{w}, t)-E_{t} \int_{0}^{\infty} e^{-\delta s} p(t+s) f(t, t+s) d s\right]
$$

where $\bar{V}(t):=\rho V^{u}(t)-u(b)-\frac{d}{d t} V^{u}(t)$ and $h(\hat{w}, t):=\int_{0}^{\infty} e^{-\delta s} p(t+s)[z(t+s)-\hat{w} f(t, t+s)] d s$ is entrepreneurial operating profit per worker. For equilibrium contracts $h\left(w^{i}(t, t), t\right)>0$. Examining the derivative, the term in brackets is strictly decreasing in $\hat{w}>\underline{w}$. Close to $\underline{w}$ the derivative is positive and unbounded. As the wage increases it eventually becomes negative as $h(\hat{w}, t)$ becomes zero. The unique point where the derivative is zero is characterized by the equation in the lemma.

Hence in equilibrium all entrepreneurs offer the same contract: $\theta^{i}(t)=\theta(t), \sigma^{i}(t)=\sigma(t) \forall \mathcal{F}_{t}, t \geq 0, i$.

Lemma A.3. In equilibrium: $\kappa=q(\theta(t)) F_{p}(t)$ for all $\mathcal{F}_{t}, t \geq 0$.

\footnotetext{
${ }^{41}$ If one contract has $V^{i}-V^{u}>0$, then all equilibrium contracts must. A situation where this would not hold is if $z(t)=b$ always. Then entrepreneurs must pay workers $b$, their unemployment consumption level in wages, but will not be able to make any profit doing so. Because hiring is costly, vacancy-creation is driven to zero.
} 
Pf. If a positive measure of vacancies is to be posted, profits from posting a vacancy must be non-negative: $-\kappa+q(\theta(t)) F_{p}(t) \geq 0$. Vacancies enter into the budget constraint linearly. If profits from vacancy posting were strictly positive, an infinite amount of vacancies would be posted, $\theta$ would be infinitely large and hence $q(\theta)$ would be zero. If the present value of output is bounded, as it should be in equilibrium, the present value from a contract, $F_{p}(t)$, is bounded from above. Then $-\kappa+q(\theta(t)) F_{p}(t)<0$ and we have a contradiction. Hence $-\kappa+q(\theta(t)) F_{p}(t)=0$.

In equilibrium entrepreneurs must be indifferent between investing into vacancies or the asset market and so the present value of posting vacancies must be zero. The linear technology implies it is not pinned down which entrepreneur actually hires workers.

Entrepreneur Consumption: The second part of the entrepreneur's problem $(\mathbb{P})$ is the consumption problem:

Given prices $p(t)>0$, for all $\mathcal{F}_{t}, t \geq 0$,

$$
\begin{aligned}
& \max _{c^{i}(t)} E_{0} \int_{0}^{\infty} e^{-\rho t} u\left(c^{i}(t)\right) d t \\
& \text { s.t. } E_{0} \int_{0}^{\infty} p(t) c^{i}(t) d t=W_{T O T}^{i} \text {, with } \\
& \qquad W_{T O T}^{i}:=E_{0} \int_{0}^{\infty} p(t) \int_{-\infty}^{0} n^{i}(\tau, t)\left[z(t)-w^{i}(\tau, t)\right] d \tau d t+W_{0}^{i} \text { given. }
\end{aligned}
$$

Lemma A.4. As long as initial wealth $W_{T O T}^{i}$ is not negative, given equilibrium prices, the consumption problem (P2) has a unique solution, characterized by

$$
e^{-\rho s} \frac{u^{\prime}\left(c^{i}(t+s)\right)}{u^{\prime}\left(c^{i}(t)\right)}=\frac{p(t+s)}{p(t)} \text { for all } t, s \geq 0, \mathcal{F}_{t} \subset \mathcal{F}_{t+s} .
$$

Pf. This is a standard problem, where a unique bounded optimum is characterized by the FOC.

\section{Proof of Proposition 2.1 Aggregation}

(a) Aggregating up the multi-agent problem allocations for $c^{i}, v^{i}, n^{i}$ along with the economy-wide $\theta, \sigma$ one obtains a feasible possible solution to the representative entrepreneur's problem with the initial conditions described in Proposition 2.1. This possible solution satisfies the optimality conditions and other equilibrium conditions of the representative entrepreneur equilibrium, so it must constitute such an equilibrium.

(b) Each entrepreneur in the multi-agent problem consumes a constant fraction of the aggregate over time: $c^{i}(t)=d^{i} c(t)$. The budget constraint pins down the individual $d^{i}$ according to wealth and income: $d^{i} E_{0} \int_{0}^{\infty} p(t) c(t) d t=W_{0}^{i}+E_{0} \int_{0}^{\infty} \int_{-\infty}^{0} p(t) n^{i}(\tau, t)\left[z(t)-w^{i}(\tau, t)\right] d \tau d t$. Given a representative entrepreneur equilibrium and individual initial conditions, one can then back out an equilibrium for the multi-agent case.

\section{Proof of Proposition 2.2 Characterization}

(a) Assume a representative entrepreneur equilibrium exists. Condition 1 holds because of Lemma 2.1, part 2. Condition 2 holds because of Lemma A.2 and the implication of Lemma 2.1, part 2 for prices. Condition 3 holds because of Lemma 2.1. part 3 and the implication of Lemma 2.1 part 2 for prices. Condition 4 is the goods market clearing condition combined with labor market clearing. Condition 5 is the dynamic equation for unemployment value. Condition 6 is the dynamic equation for unemployment.

(b) Given variables $V^{u}(t), c(t), \theta(t), \sigma(t), n_{u}(t)$ satisfying the conditions of Proposition 2.2 for all $t \geq 0$, one can use the consumption path $c(t)$ to construct prices for which $c(t), \theta(t), \sigma(t)$ satisfy the optimality conditions of the agent $\left(\frac{p(t+s)}{p(t)}:=e^{-\rho s} \frac{u^{\prime}(c(t+s))}{u^{\prime}(c(t))}\right)$ and with $v(t)=\theta(t) n_{u}(t)$, these are budget feasible for the agent as well as clear markets. 
Proof of Lemma 3.1 1. Reduce the steady-state equations into one equation in the wage:

$$
\frac{z-w}{\rho+\delta}\left[\rho+\delta+k\left(\frac{z-w}{\rho+\delta} \frac{k}{\kappa}\right)^{\frac{1-\alpha}{\alpha}}\right]=\frac{1-\alpha}{\alpha} w \ln (w / b) .
$$

This equation has a unique solution $w \in(b, z)$. The other variables can be expressed as functions of the wage:

$$
\theta=q^{-1}\left(\frac{\kappa(\rho+\delta)}{z-w}\right), \quad m=\frac{\mu(\theta)}{\mu(\theta)+\delta}, \quad c=\frac{\rho \kappa}{q(\theta)+\delta / \theta}, \quad a=\Phi=\frac{w}{c} .
$$

2. Equation (12) determines $a$ : $\frac{Y}{a}=\frac{1-\alpha}{\alpha}\left(\frac{\ln a}{\rho+\delta}+X\right)+\frac{1}{\rho+\delta}$. Given that $Y$ is positive, there is a unique strictly positive solution for any $X$. In steady-state $\bar{Y}-\frac{\bar{a}}{\rho+\delta}=\frac{1}{\bar{c}} \frac{z-\bar{w}}{\rho+\delta}>0$ and hence $Y-\frac{a}{\rho+\delta}$ is positive when $Y, X$ are close to steady-state. The equation is continuously differentiable in $a, X, Y$ and the derivative w.r.t $a$ is non-zero, so that according to the implicit function theorem one can solve for a differentiable $\tilde{a}(X, Y)$ with continuous partial derivatives.

From equation (13), we have $c=\frac{\kappa}{q(\theta)\left(Y-\frac{a(X, Y)}{\rho+\delta}\right)}$ and plugging this into equation (14): $c(1+m \Phi)=m z-$ $\kappa \theta(1-m)$, one can show that a unique solution $\theta>0$ exists. Because the expression is continuously differentiable, and the partial w.r.t. $\theta$ is non-zero, there exists a continuously differentiable $\theta(m, \Phi, X, Y)$. This then extends to $c$ by the expression above.

3. The result on the eigenvalues is shown by considering the characteristic polynomial $\pi(x)=\operatorname{det}(A-x I)$, where $A$ is the system matrix. We know that $\pi(x)=\left(\lambda_{1}-x\right)\left(\lambda_{2}-x\right)\left(\lambda_{3}-x\right)\left(\lambda_{4}-x\right)$. By tedious algebra, one can show that $\pi(0)>0, \pi(\rho)=0, \pi(\rho+\delta)<0, \pi(-\delta)<0$. Details available upon request.

Proof of Proposition 3.1 Unique Equilibrium Path The statement is that there is a unique point in the stable manifold that will, when mapped with an orthogonal projection to the $(m, \Phi)$-plane, map onto the point $(m, \Phi)$. The system is smooth and hyperbolic, so the theory of differential equations gives useful results. Consider first the linearized system. The stable subspace is spanned by the two stable eigenvectors, denote them by $v^{1}, v^{2}$. Points in that space can be represented as linear combinations $d^{1} v^{1}+d^{2} v^{2}$ for some $d^{1}, d^{2} \in \mathbb{R}$. Points corresponding to $(m, \Phi)$ must satisfy $d^{1} v_{1: 2}^{1}+d^{2} v_{1: 2}^{2}=(m, \Phi)^{\prime}$, which means that a unique representation exists iff the vectors $v_{1: 2}^{1}, v_{1: 2}^{2}$ are linearly independent. To consider the original system then, note that the stable manifold is both smooth and tangent to the stable subspace at the steady-state.

\section{Appendix B Other CRRA Preferences}

This section shows how to derive the reduced state space representation for constant relative risk aversion preferences not of the log-form, also allowing preference heterogeneity between workers and entrepreneurs. I consider preferences of form $u(c)=\frac{c^{1-\gamma}}{1-\gamma}$, with $0<\gamma \neq 1$, and denote the preference parameters of entrepreneurs by $\{\gamma, \rho\}$ and workers by $\{\hat{\gamma}, \hat{\rho}\}$. For purposes of illustration I abstract from aggregate shocks.

Optimal contracts equate marginal rates of substitution across employer and employee, so

$$
e^{-\rho s}\left(\frac{c(t+s)}{c(t)}\right)^{-\gamma}=e^{-\hat{\rho} s}\left(\frac{w(t, t+s)}{w(t, t)}\right)^{-\hat{\gamma}} \Rightarrow \frac{w(t, t+s)}{w(t, t)}=e^{-\frac{\hat{\rho}-\rho}{\hat{\gamma}} s}\left(\frac{c(t+s)}{c(t)}\right)^{\frac{\gamma}{\gamma}},
$$

for any $\mathcal{F}_{t}, t \geq 0, s \geq 0$ and $\mathcal{F}_{t+s}$ a continuation of $\mathcal{F}_{t}$. Hence we can write $w(t, t+s)=e^{-\frac{\hat{\rho}-\rho}{\gamma} s} a(t) c(t+s)^{\frac{\gamma}{\gamma}}$, where $a(t):=w(t, t) c(t)^{-\frac{\gamma}{\gamma}}$.

The sensitivity of wages to current aggregate conditions depends on $\gamma / \hat{\gamma}$. If $\gamma$ is zero, entrepreneurs have linear preferences and insure workers against changes in aggregate conditions during the contract. If workers 
are less patient than entrepreneurs, the contract wage is front-loaded, trending down over time. How strong this effect is depends on the workers' preferences about smoothing consumption, $\hat{\gamma}$.

The cross sectional dispersion in wages is captured by the $e^{-\frac{\hat{\rho}-\rho}{\hat{\gamma}} s} a(t)$-terms. I define an employment weighted average of these as $\Phi(t):=\frac{1}{m(t)} \int_{-\infty}^{t} n(\tau, t) e^{-\frac{(\hat{\rho}-\rho)}{\hat{\gamma}}(t-\tau)} a(\tau) d \tau$, where $m, n$ are measures of employment as before. The law of motion for $\Phi$ reads

$$
\dot{\Phi}(t)=\frac{\mu(\theta(t))(1-m(t))}{m(t)}[a(t)-\Phi(t)]-\frac{(\hat{\rho}-\rho)}{\hat{\gamma}} \Phi(t),
$$

where the last term captures any trending in contract wages over time.

To express the equilibrium conditions in Proposition 2.2 using state variables $m, \Phi$, I define the auxiliary variables:

$$
\begin{aligned}
X^{1}(t) & :=\int_{0}^{\infty} e^{-\left(\rho+\delta+\frac{(\hat{\rho}-\rho)}{\hat{\gamma}}\right) s} \frac{c(t+s)^{\frac{\gamma}{\gamma}(1-\hat{\gamma})}}{1-\hat{\gamma}} d s, \\
X^{2}(t) & :=\delta \int_{0}^{\infty} e^{-(\hat{\rho}+\delta) s} V^{u}(t+s) d s-V^{u}(t), \\
Y(t) & :=\int_{0}^{\infty} e^{-(\rho+\delta) s} c(t+s)^{-\gamma} z d s .
\end{aligned}
$$

The laws of motion for these variables read 42

$$
\begin{aligned}
& \left(\rho+\delta+\frac{(\hat{\rho}-\rho)}{\hat{\gamma}}\right) X^{1}(t)=\frac{c(t)^{\frac{\gamma}{\gamma}(1-\hat{\gamma})}}{1-\hat{\gamma}}+\dot{X}^{1}(t), \\
& (\hat{\rho}+\delta) X^{2}(t)=-\frac{b^{1-\hat{\gamma}}}{1-\hat{\gamma}}-\mu(\theta(t))\left[a(t)^{1-\hat{\gamma}} X^{1}(t)+X^{2}(t)\right]+\dot{X}^{2}(t), \\
& (\rho+\delta) Y(t)=c(t)^{-\gamma} z+\dot{Y}(t) .
\end{aligned}
$$

Notice that $F(t)$ and $V(t)-V^{u}(t)$ satisfy

$$
F(t)=\int_{0}^{\infty} e^{-(\rho+\delta) s}\left(\frac{c(t+s)}{c(t)}\right)^{-\gamma}\left[z-e^{-\frac{\hat{\rho}-\rho}{\hat{\gamma}} s} a(t) c(t+s)^{\frac{\gamma}{\hat{\gamma}}}\right] d s=c(t)^{\gamma}\left[Y(t)-a(t) X^{1}(t)(1-\hat{\gamma})\right]
$$

and

$$
V(t)-V^{u}(t)=\int_{0}^{\infty} e^{-(\hat{\rho}+\delta) s}\left[\frac{\left(e^{-\frac{\hat{\rho}-\rho}{\hat{\gamma}} s} a(t) c(t+s)^{\frac{\gamma}{\hat{\gamma}}}\right)^{1-\hat{\gamma}}}{1-\hat{\gamma}}+\delta V^{u}(t+s)\right] d s-V^{u}(t)=a(t)^{1-\hat{\gamma}} X^{1}(t)+X^{2}(t) .
$$

Taking advantage of this, the algebraic equations determining $a, c, \theta$, (corresponding to (12)-(14) ) become

$$
\begin{aligned}
& \frac{1-\alpha}{Y(t)-a(t) X^{1}(t)(1-\hat{\gamma})}=\frac{\alpha}{a(t) \hat{\gamma}\left[a(t)^{1-\hat{\gamma}} X^{1}(t)+X^{2}(t)\right]}, \\
& \kappa=q(\theta(t)) c(t)^{\gamma}\left[Y(t)-a(t) X^{1}(t)(1-\hat{\gamma})\right], \\
& c(t)=m(t) z-m(t) \Phi(t) c(t)^{\frac{\gamma}{\gamma}}-\kappa \theta(t)(1-m(t)) .
\end{aligned}
$$

We have arrived at a system of five differential equations in predetermined states $m$, $\Phi$ and jump-states $X^{1}, X^{2}, Y$ given by (10), (18)-(21) with the algebraic equations (23)-(24) determining $a, c, \theta$. One can proceed exactly as in the log-utility case, with one additional jump variable 43

\footnotetext{
${ }^{42}$ We have $X^{2}(t)=\Delta t \delta V^{u}(t)+e^{-(\hat{\rho}+\delta) \Delta t}\left[X^{2}(t+\Delta t)+V^{u}(t+\Delta t)\right]-V^{u}(t) \approx \Delta t \delta V^{u}(t)+X^{2}(t)-(\hat{\rho}+\delta) \Delta t\left[X^{2}(t)+\right.$ $\left.V^{u}(t)\right]+\Delta t\left[\dot{X}^{2}(t)+\dot{V}^{u}(t)\right]$, which implies $(\hat{\rho}+\delta) X^{2}(t)=-\hat{\rho} V^{u}(t)+\dot{V}^{u}(t)+\dot{X}^{2}(t)$. Combining this with the equation for $V^{u}(t), \hat{\rho} V^{u}(t)=\frac{b^{1-\hat{\gamma}}}{1-\hat{\gamma}}+\mu(\theta(t))\left[a(t)^{1-\hat{\gamma}} X^{1}(t)+X^{2}(t)\right]+\dot{V}^{u}(t)$, implies the equation in the text.

${ }^{43}$ If workers have log preferences, this needs to be augmented slightly.
} 


\section{Appendix C Steady-State}

For convenience, one can write $\Delta(x, \gamma)=\frac{x^{-\gamma}}{\frac{\left[x^{1}-\gamma-1\right]}{1-\gamma}}[x-1]$, where $x=\frac{w}{b} \geq 1$. To see that $\Delta(x, \gamma)$ decreases in $\gamma$, note first that $x^{1-\gamma}=e^{(1-\gamma) \ln x}>1+(1-\gamma) \ln x$ for all $\gamma \neq 1$. It follows then that for $x>1$,

$$
\frac{d}{d \gamma} \ln \Delta=-\frac{1}{1-\gamma}-\ln x+\frac{x^{1-\gamma} \ln x}{x^{1-\gamma}-1}=-\frac{1}{1-\gamma}+\frac{\ln x}{x^{1-\gamma}-1}<0
$$

To see that $\Delta(x, \gamma)$ decreases in $x>1$, note first that $\frac{x^{1-\gamma}-1}{1-\gamma}<x-1$ for $x>1$, because the left hand side is concave in $x$. It follows then that

$$
\frac{d}{d x} \ln \Delta=\frac{1}{x-1}-\frac{\gamma}{x}-\frac{(1-\gamma) x^{-\gamma}}{x^{1-\gamma}-1}=\frac{1}{x(x-1)}\left[1-(x-1) \frac{1-\gamma}{x^{1-\gamma}-1}\right]<0 .
$$

The figures shown in the text always perform a re-calibration of the vacancy-cost to keep the steady-state level of unemployment fixed (by imposing that in steady-state $\theta=1$ ) 44 This means that as $\gamma$ is increased, vacancy-costs rise as well, and the latter tends to dampen fluctuations. Figure 8 shows what happens without this re-calibration. Comparing the outcomes to Figures 2 and 3 , one can see a slightly stronger response of both the vacancy-unemployment ratio and the wage to productivity. It still remains true that wage responses decrease as $\gamma$ increases. For the level effects shown below, the pattern is similar in terms of $\gamma$ increasing the response of the vacancy-unemployment ratio and decreasing the response of the wage, but the magnitudes reflect the fact that the levels of $\theta, w$ change in $b, \gamma$.

If the preferences of workers and entrepreneurs differ as discussed in Appendix B, the steady-state values in Section 3.1 reduce to:

$$
F=\frac{z}{\rho+\delta}-\frac{w}{\rho+\delta+\frac{\hat{\rho}-\rho}{\hat{\gamma}}}, \text { and } V-V^{u}=\frac{1}{1-\hat{\gamma}}\left[\frac{w^{1-\hat{\gamma}}}{\rho+\delta+\frac{\hat{\rho}-\rho}{\hat{\gamma}}}-\frac{b^{1-\hat{\gamma}}}{\hat{\rho}+\delta}\right] \frac{\hat{\rho}+\delta}{\left[\hat{\rho}+\delta+k\left(F \frac{k}{\kappa}\right)^{\frac{1-\alpha}{\alpha}}\right]} .
$$

Clearly the entrepreneurial $\gamma$ does not affect the steady-state, but only the workers' $\hat{\gamma}$.

\footnotetext{
${ }^{44}$ Fixing the level of unemployment by imposing $\theta=1$ implies that $z-w=\frac{\kappa(\rho+\delta)}{q(1)}$ and the steady-state wage equation becomes an equation in $\kappa$ instead

$$
\frac{1-\alpha}{\frac{\kappa}{k}}=\frac{\alpha\left[z-\frac{\kappa}{k}(\rho+\delta)\right]^{-\gamma}}{\frac{\left[\left(z-\frac{\kappa}{k}(\rho+\delta)\right)^{1-\gamma}-b^{1-\gamma}\right]}{1-\gamma}}(\rho+\delta+k), \text { for } \gamma \neq 1 .
$$
}



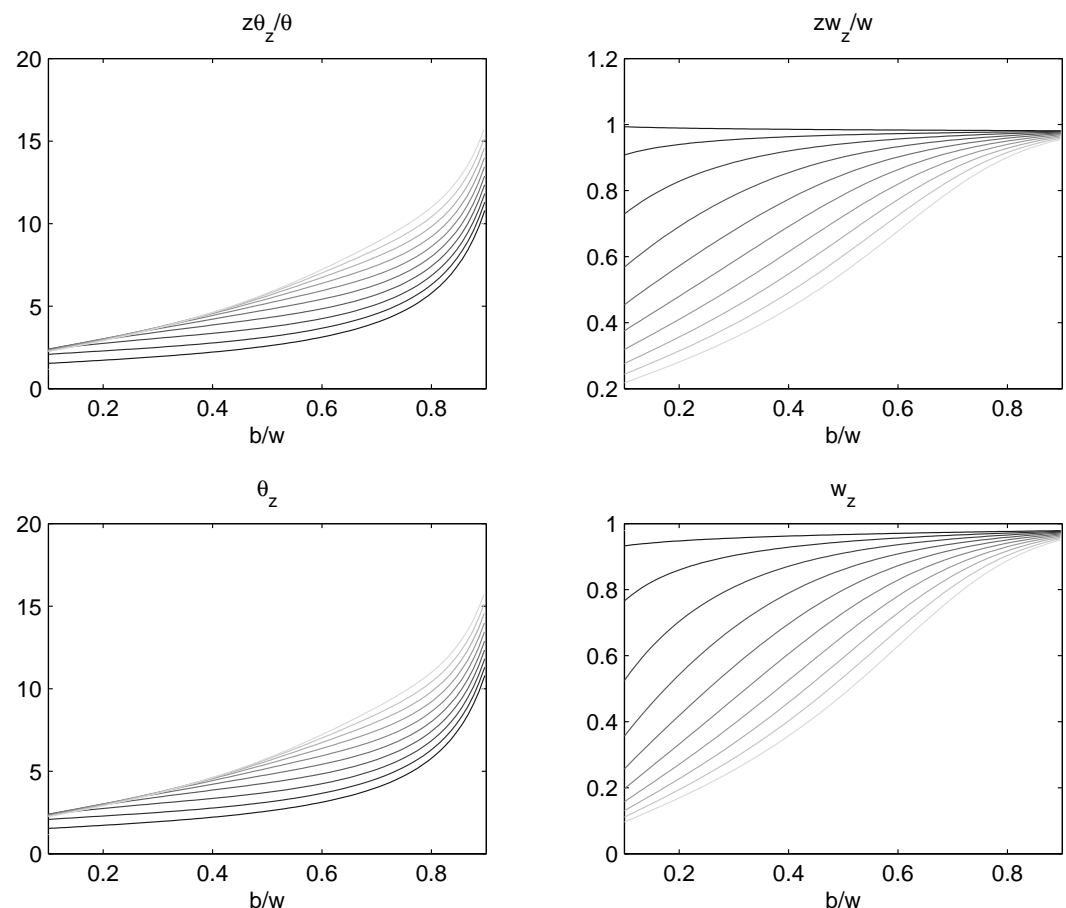

Figure 7: Steady-state responses to permanent productivity changes
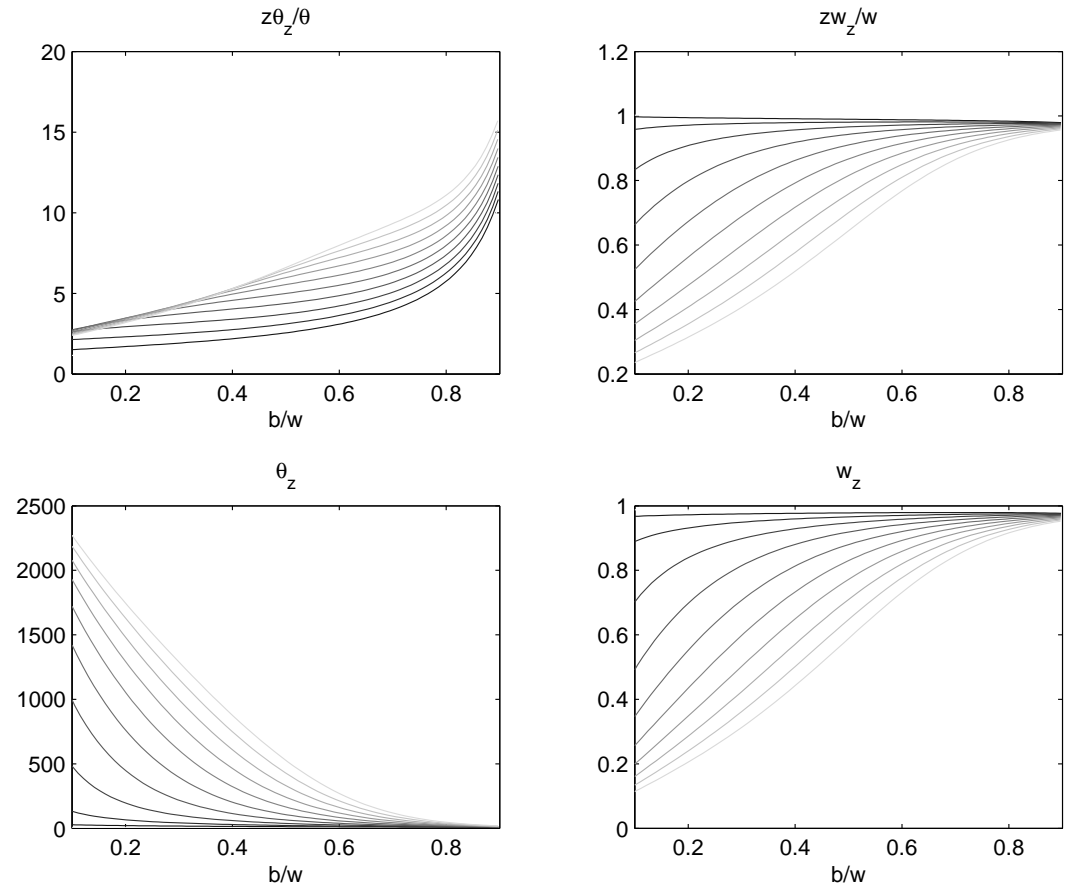

Figure 8: Steady-state responses to permanent productivity changes without re-calibration

Notes: The figures plot the responses of the steady-state vacancy-unemployment ratio and wage to changes in steady-state productivity. The first re-calibrates to keep $\theta$ (and hence unemployment) fixed, the second does not. Risk aversion levels $\gamma=0,1 \ldots 10$ grey color fades out with higher $\gamma$. 


\section{References}

Acemoglu, D., And R. Shimer (1999): "Efficient Unemployment Insurance," Journal of Political Economy, 107(5), 893-928.

(2000): "Productivity Gains from Unemployment Insurance," European Economic Review, $44,1195-1224$.

Aguiar, M., And E. Hurst (2005): "Consumption versus Expenditure," Journal of Political Economy, 113(5), 919-948.

Andolfatto, D. (1996): "Business Cycles and Labor Market Search," American Economic Review, 86(1), 112- 132 .

Azariadis, C. (1975): "Implicit Contracts and Underemployment Equilibria," Journal of Political Economy, 83(6), 1183- 202.

Baily, M. N. (1974): "Wages and Employment under Uncertain Demand," Review of Economic Studies, 41(1), 37- 50.

Barlevy, G. (2001): "Why Are the Wages of Job Changers So Procyclical?," Journal of Labor Economics, 19(4), 837-878.

Beaudry, P., and J. Dinardo (1991): "The Effect of Implicit Contracts on the Movement of Wages over the Business Cycle: Evidence from Micro Data," Journal of Political Economy, 99(4), $665-688$.

BiLs, M. (1985): "Real Wages over the Business Cycle: Evidence from Panel Data," Journal of Political Economy, 93(4), 666- 89.

Bils, M., Y. Chang, and S.-B. Kim (2007): "Comparative Advantage in Cyclical Unemployment," NBER Working Paper No. W13231.

Bishow, J., And D. O. Parsons (2004): "Trends in Severance Pay Coverage in the United States, 1980-2001," Unpublished Manuscript, George Washington University.

Boldrin, M., and M. Horvath (1995): "Labor Contracts and Business Cycles," Journal of Political Economy, 103(5), 972- 1004.

Browning, M., and T. F. Crossley (2001): "Unemployment Insurance Benefit Levels and Consumption Changes," Journal of Public Economics, 80, 1- 23.

Brügemann, B., And G. Moscarini (2007): "Rent Rigidity, Asymmetric Information, and Volatility Bounds in Labor Markets," Unpublished Manuscript, Yale University.

Campbell, J. Y., and N. G. Mankiw (1990): "Consumption, Income, and Interest Rates: Reinterpreting the Time Series Evidence," NBER working paper no. 2924.

Chetty, R. (2008): "Moral Hazard vs. Liquidity and Optimal Unemployment Insurance," Journal of Political Economy, 116(2), 173-234. 
Costain, J. S., and M. Reiter (2003): "Business Cycles, Unemployment Insurance, and the Calibration of Matching Models," CESifo working paper, (1008).

(2005): "Stabilization versus Insurance: Welfare Effects of Procyclical Taxation under Incomplete Markets," Unpublished Manuscript, Universitat Pompeu Fabra.

Danthine, J. P., And J. B. Donaldson (1992): "Risk Sharing in the Business Cycle," European Economic Review, 36, 468-475.

Gertler, M., And A. Trigari (2006): "Unemployment Fluctuations with Staggered Nash Wage Bargaining," Unpublished Manuscript, New York University.

Gomme, P., And J. Greenwood (1995): "On the Cyclical Allocation of Risk," Journal of Economic Dynamics and Control, 19, 91- 124.

Gruber, J. (1997): "The Consumption Smoothing Benefits of Unemployment Insurance," American Economic Review, 87, 192- 205.

Guiso, L., L. Pistaferri, and F. Schivardi (2005): "Insurance within the Firm," Journal of Political Economy, 113(5), 1054- 87.

Haefke, C., T. van Rens, and M. Sonntag (2007): "Wage Rigidity and Job Creation," Unpublished Manuscript, Institute for Advanced Studies, Vienna.

Hagedorn, M., And I. Manovskit (2006): "The Cyclical Behavior of Equilibrium Unemployment and Vacancies Revisited," American Economic Review, forthcoming.

Hall, R. E. (2005): "Employment Fluctuations with Equilibrium Wage Stickiness," American Economic Review, pp. 50-65.

Hall, R. E., and P. R. Milgrom (2007): "The Limited Influence of Unemployment on the Wage Bargain," American Economic Review, forthcoming.

Hall, R. E., And F. S. Mishkin (1982): "The Sensitivity of Consumption to Transitory Income: Estimates from Panel Data on Households," Econometrica, pp. 461-81.

Hosios, A. J. (1990): "On the Efficiency of Matching and Related Models of Search and Unemployment," Review of Economic Studies, p. 27998.

JAPPELli, T. (1990): "Who is Credit Constrained in the U.S. Economy?," Quartely Journal of Economics, 105(1), 219- 234.

Kennan, J. (2007): "Private Information, Wage Bargaining and Employment Fluctuations," Unpublished Manuscript, University of Wisconsin.

Kinlstrom, R. E., And J.-J. LAfFont (1979): "A General Equilibrium Entrepreneurial Theory of Firm Formation Based on Risk Aversion," Journal of Political Economy, 87(4), 719- 748.

Knight, F. H. (1921): Risk, Uncertainty, and Profit. Houghton Mifflin Company.

Krusell, P., T. Mukoyama, and A. Sahin (2007): "Labor-Market Matching with Precautionary Savings and Aggregate Fluctuations," Unpublished Manuscript, Princeton University. 
Kudlyak, M. (2007): "The Cyclicality of the User Cost of Labor with Search and Matching," Unpublished Manuscript, University of Rochester.

Mankiw, N. G., And S. P. Zeldes (1991): "The Consumption of Stockholders and Nonstockholders," Journal of Financial Economics, 29, 97-112.

McDonald, J. T., and C. Worswick (1999): "Wages, Implicit Contracts, and the Business Cycle: Evidence from Canadian Micro Data," Journal of Political Economy, 107(4), 884-892.

Menzio, G., And S. Shi (2008): "On-the-Job Search and Business Cycles," Unpublished Manuscript, University of Toronto.

Merz, M. (1995): "Search in the Labor Market and the Real Business Cycle," Journal of Monetary Economics, 36, 269-300.

Moen, E. R. (1997): "Competitive Search Equilibrium," Journal of Political Economy, 105(2), $385-411$.

Montgomery, J. D. (1991): "Equilibrium Wage Dispersion and Interindustry Wage Differentials," Quarterly Journal of Economics, 106, 163-79.

Mortensen, D. T., and C. A. Pissarides (1994): "Job Creation and Job Destruction in the Theory of Unemployment," Review of Economic Studies, 61, 397-415.

NAGYPÁL, É. (2006): "Labor-Market Fluctuations, On-the-Job Search, and the Acceptance Curse," Unpublished Manuscript, Northwestern University.

Nakajima, M. (2008): "Business Cycles in the Equilibrium Model of Labor Market Search and Self-insurance," Unpublished Manuscript, University of Illinois at Urbana-Champaign.

Peters, M. (1991): "Ex Ante Price Offers in Matching Games with Non-Steady States," Econometrica, pp. 1425-54.

Pissarides, C. A. (1985): "Short-Run Equilibrium Dynamics of Unemployment, Vacancies, and Real Wages," American Economic Review, 75(4), 676- 690.

(2007): "The Unemployment Volatility Puzzle: Is Wage Stickiness the Answer?," Unpublished Manuscript, London School of Economics.

Rudanko, L. (2008): "Labor Market Dynamics under Long Term Wage Contracting," Unpublished Manuscript, Boston University.

Shao, E., And P. Silos (2007): "Uninsurable Individual Risk and the Cyclical Behavior of Unemployment and Vacancies," Federal Reserve Bank of Atlanta Working Paper 2007-5.

Shimer, R. (2005a): "The Cyclical Behavior of Equilibrium Unemployment and Vacancies," American Economic Review, pp. 25-49.

(2005b): "Reassessing the Ins and Outs of Unemployment," Unpublished Manuscript, University of Chicago.

Shin, D. (1994): "Cyclicality of Real Wages among Young Men," Economics Letters, 46, 137-42. 
Sigouin, C. (2004): "Self-enforcing employment contracts and business cycle fluctuations," Journal of Monetary Economics, 51, 339-373.

Solon, G., R. BArsky, And J. PARker (1994): "Measuring the Cyclicality of Real Wages: How Important Is Composition Bias?," Quarterly Journal of Economics, 109, 1-26.

Stephens, M. (2001): "The Long Run Consumption Effects of Earnings Shocks," Review of Economics and Statistics, 83, 28-36.

Storesletten, K., C. I. Telmer, and A. Yaron (2004): "Cyclical Dynamics in Idiosyncratic Labor Market Risk," Journal of Political Economy, 112(3), 695- 717.

Zeldes, S. P. (1989): "Consumption and Liquidity Constraints: An Empirical Investigation," Journal of Political Economy, 97, 305-346. 


\section{Supplementary Appendixes}

\section{Appendix D Solving for Equilibrium with Aggregate Shocks}

This section describes the approach used to solve for equilibrium with aggregate shocks. For purposes of illustration, I focus on the log-utility case, but the same strategy extends directly to the cases in Appendix B

Calibrating the Productivity Process As discussed on page 5, aggregate shocks arrive at Poisson rate $\eta$ and when the shock hits, the value of $z$ jumps. I assume the new value of productivity $z^{\prime}$, conditional on the prevailing value $z$, satisfies $z^{\prime}-\bar{z} \mid z \sim N\left(\xi(z-\bar{z}), \sigma_{\epsilon}^{2}\right)$, where the draws are independent, $\xi \in(0,1)$ and the variance $\sigma_{\epsilon}^{2}$ is small.

The target series for the productivity process is the non-farm business sector labor productivity series reported by the Bureau of Labor Statistics. Taking logs and $H P\left(10^{5}\right)$-filtering 45 the quarterly series has autocorrelation 0.89 and standard deviation 0.02 . The parameters of the productivity process $\left(\xi, \sigma_{\epsilon}, \eta\right)$ are set to match these figures as follows: For given $\left(\xi, \sigma_{\epsilon}, \eta\right)$, compute the corresponding simulated moments from the model. (I compute averages of these moments from 100 realizations of simulated monthly data for 55 years, which is aggregated to quarters, logged and filtered before calculating the sample moment. I set $\eta=0.1$, which leaves $\xi, \sigma_{\epsilon}$ to be pinned down by the two empirical moments (standard deviation and autocorrelation). If one observed $z$ with unit intervals, the observed process would have autocorrelation $\rho_{z}:=1-\eta+\eta \xi$ and variance $\sigma_{z}^{2}:=\frac{\eta^{2} \sigma_{\epsilon}^{2}}{1-\rho_{z}^{2}}$. To obtain the observed moments, I use input values $\xi=0.768$, $\sigma_{\epsilon}=0.0191$. For impulse responses hence $\rho_{z}=0.977$.

Computing Simulated Moments To compute the reported moments from the model, I feed into the model simulated monthly productivity data. For each 55 years worth of data I aggregate to quarters, take logs, $H P\left(10^{5}\right)$-filter and calculate moments, then averaging over 100 samples.

Solving the Model Having shocks to $z$ does not change how wages and entrepreneurial consumption co-move in equilibrium, and the average consumption share $\Phi$ remains a key state variable for collapsing the state space of the problem. As in the case without aggregate shocks, I consider equilibria where the state of the economy is fully characterized by the current values of $\psi:=(m, \Phi, z)$. With no aggregate shocks we know that if $(m, \Phi)$ is close to steady-state, generically there exist unique values of $X, Y$ that guarantee convergence to the steady-state. The equilibrium path can thus be represented by $(m, \Phi, \hat{X}(m, \Phi), \hat{Y}(m, \Phi))$, where $\hat{X}(m, \Phi), \hat{Y}(m, \Phi)$ take on these unique values. Analogously, postulate that to each $\psi$, there corresponds a unique pair $\hat{X}(\psi), \hat{Y}(\psi)$, corresponding to equilibrium in the presence of shocks. The equilibria represented by $(\psi, \hat{X}(\psi), \hat{Y}(\psi))$ must satisfy a dynamic system analogous to (10)-(16). With aggregate shocks arriving at Poisson rate $\eta$ this system can be written in terms of $\hat{X}, \hat{Y}$ as:

$$
\begin{aligned}
& 0=F(\psi, \hat{X}(\psi), \hat{Y}(\psi))+\eta E\left[\hat{X}\left(\psi^{\prime}\right)-\hat{X}(\psi) \mid \psi\right]+\hat{X}_{m}(\psi) f(\psi, \hat{X}(\psi), \hat{Y}(\psi))+\hat{X}_{\Phi}(\psi) g(\psi, \hat{X}(\psi), \hat{Y}(\psi)), \\
& 0=G(\psi, \hat{X}(\psi), \hat{Y}(\psi))+\eta E\left[\hat{Y}\left(\psi^{\prime}\right)-\hat{Y}(\psi) \mid \psi\right]+\hat{Y}_{m}(\psi) f(\psi, \hat{X}(\psi), \hat{Y}(\psi))+\hat{Y}_{\Phi}(\psi) g(\psi, \hat{X}(\psi), \hat{Y}(\psi))
\end{aligned}
$$

\footnotetext{
${ }^{45}$ for consistency with the treatment of unemployment and vacancies adopted in the literature since Shimer (2005a)
} 
where $\psi^{\prime}:=\left(m, \Phi, z^{\prime}\right)$ and

$$
\begin{aligned}
f(\psi, X, Y) & :=-\delta m+\mu(\tilde{\theta}(\psi, X, Y))(1-m), \\
g(\psi, X, Y) & :=\frac{\mu(\tilde{\theta}(\psi, X, Y))(1-m)}{m}[\tilde{a}(\psi, X, Y)-\Phi], \\
F(\psi, X, Y) & :=-(\delta+\rho) X+\ln \tilde{c}(\psi, X, Y)-\ln b-\mu(\tilde{\theta}(\psi, X, Y))\left[\frac{\ln \tilde{a}(\psi, X, Y)}{\rho+\delta}+X\right], \\
G(\psi, X, Y) & :=-(\delta+\rho) Y+\frac{z}{\tilde{c}(\psi, X, Y)} .
\end{aligned}
$$

The functions $\tilde{a}, \tilde{c}, \tilde{\theta}$ are based on Lemma 3.1. The problem is now one of solving a system of partial differential equations, where one needs to further specify boundary conditions to guarantee stability. Because the labor productivity shocks associated with business cycles are small, I use a linearization approach with linearizations done around the steady-state corresponding to average productivity. Denoting this steady-state as $\bar{m}, \bar{\phi}, \bar{z}$, we have

$$
\begin{aligned}
& \hat{X}(m, \Phi, z) \approx \bar{X}+\bar{X}_{m}(m-\bar{m})+\bar{X}_{\Phi}(\Phi-\bar{\Phi})+\bar{X}_{z}(z-\bar{z}), \\
& \hat{Y}(m, \Phi, z) \approx \bar{Y}+\bar{Y}_{m}(m-\bar{m})+\bar{Y}_{\Phi}(\Phi-\bar{\Phi})+\bar{Y}_{z}(z-\bar{z}),
\end{aligned}
$$

where $\bar{X}:=\hat{X}(\bar{m}, \bar{\Phi}, \bar{z}), \bar{Y}:=\hat{Y}(\bar{m}, \bar{\Phi}, \bar{z})$ and $\bar{X}_{m}, \bar{X}_{\Phi}, \bar{X}_{z}, \bar{Y}_{m}, \bar{Y}_{\Phi}, \bar{Y}_{z}$ are the corresponding partial derivatives evaluated at the steady-state. The unknowns are these partial derivatives, along with the steady-state. The derivatives can be found by differentiating the system (25) with respect to $m, \Phi, z$ and using the linear approximation above for $\hat{X}, \hat{Y}$. Given the assumptions about the distribution of new productivity levels, we have $E\left[\hat{X}\left(m, \Phi, z^{\prime}\right)-\hat{X}(m, \Phi, z) \mid m, \Phi, z\right] \approx \bar{X}_{z} E\left[\left(z^{\prime}-z\right) \mid m, \Phi, z\right]=\bar{X}_{z}(\xi-1)(z-\bar{z})$ and similarly for $\hat{Y}$.

Simulating Between aggregate shocks, the linearized system for $m, \Phi$ reads:

$$
\begin{aligned}
\dot{m}=\bar{f}_{m}(m-\bar{m})+\bar{f}_{\Phi}(\Phi-\bar{\Phi})+\bar{f}_{z}(z-\bar{z}) & +\bar{f}_{X}\left[\bar{X}_{m}(m-\bar{m})+\bar{X}_{\Phi}(\Phi-\bar{\Phi})+\bar{X}_{z}(z-\bar{z})\right] \\
& +\bar{f}_{Y}\left[\bar{Y}_{m}(m-\bar{m})+\bar{Y}_{\Phi}(\Phi-\bar{\Phi})+\bar{Y}_{z}(z-\bar{z})\right] \\
\dot{\Phi}=\bar{g}_{m}(m-\bar{m})+\bar{g}_{\Phi}(\Phi-\bar{\Phi})+\bar{g}_{z}(z-\bar{z}) & +\bar{g}_{X}\left[\bar{X}_{m}(m-\bar{m})+\bar{X}_{\Phi}(\Phi-\bar{\Phi})+\bar{X}_{z}(z-\bar{z})\right] \\
& +\bar{g}_{Y}\left[\bar{Y}_{m}(m-\bar{m})+\bar{Y}_{\Phi}(\Phi-\bar{\Phi})+\bar{Y}_{z}(z-\bar{z})\right]
\end{aligned}
$$

As a linear system, this has a closed form solution. Simulation can be done by drawing arrival times from an exponential distribution, drawing new productivity realizations from the appropriate normal distribution and using the closed form solution of the system to calculate paths of $m(t), \Phi(t)$.

Impulse Responses Suppose $z(0) \neq \bar{z}$, and define $\hat{z}(t):=E[z(t) \mid z(0)]-\bar{z}$. We know that $E[z(t+\Delta t)-$ $\bar{z} \mid z(t)]=\eta \Delta t \xi(z(t)-\bar{z})+(1-\eta \Delta t)(z(t)-\bar{z})$. Hence $\dot{\hat{z}}=-\eta(1-\xi) \hat{z}$ and $\hat{z}(t)=z(0) e^{-\eta(1-\xi) t}$. To find the responses of endogenous variables $\hat{m}(t):=E[m(t) \mid z(0)]-\bar{m}, \hat{\Phi}(t):=E[\Phi(t) \mid z(0)]-\bar{\Phi}$, note that the linearized system above yields the linear system

$$
\left(\begin{array}{c}
\dot{m} \\
\Phi
\end{array}\right)=\bar{A}\left(\begin{array}{c}
m-\bar{m} \\
\Phi-\bar{\Phi}
\end{array}\right)+\bar{b}(z-\bar{z}) \Rightarrow\left(\begin{array}{c}
\dot{\hat{m}} \\
\hat{\Phi}
\end{array}\right)=\bar{A}\left(\begin{array}{c}
\hat{m} \\
\hat{\Phi}
\end{array}\right)+\bar{b} \hat{z} \Rightarrow\left(\begin{array}{l}
\dot{\hat{m}} \\
\hat{\Phi} \\
\hat{z}
\end{array}\right)=\left(\begin{array}{cc}
\bar{A} & \bar{b} \\
0 & -\eta(1-\xi)
\end{array}\right)\left(\begin{array}{l}
\hat{m} \\
\hat{\Phi} \\
\hat{z}
\end{array}\right) .
$$

Quality of Linearized Solution In the absence of aggregate shocks, solving the original non-linear problem numerically is relatively straightforward, and comparing the solution of this problem with the cor- 
responding linearization based solution allows me to examine the accuracy of the linearization approach. Computing a solution to the nonlinear deterministic system involves a shooting problem with two predetermined variables and either two or three jump variables depending on the utility function used for workers 46 Perturbing the initial conditions $(m(0), \Phi(0))$ from steady-state to the steady-state of an economy with $2 \%$ higher or lower productivity and examining the adjustment paths of the two solutions, I find that the differences are practically indistinguishable to the eye.

\section{Appendix E Connection to the Mortensen-Pissarides Model}

Wage-setting in the Mortensen-Pissarides model does not involve contract posting. Vacancies are posted without specifying wages, which are determined after matching occurs through bilateral bargaining. Search is not directed, with workers deciding between attractive contracts and faster re-employment, because all posted vacancies look identical. Despite these differences, the equilibria of the two models are closely related.

\section{Equivalence with a Bargaining Equilibrium}

Consider an economy where entrepreneurs post vacancies without specifying a contract and workers search for these vacancies in a single labor market, where parties meet according to a matching function. When a worker finds a job, the worker and entrepreneur bargain bilaterally over a long-term wage contract. The solution to the bargaining problem obtains from maximizing a Nash product. Definition E.1 defines such an equilibrium and Proposition E.1 states an equivalence result relating the two.

Definition E.1. Consider an economy with entrepreneurs indexed by $i=1 \ldots N$. An equilibrium of a bargaining economy consists of, for all $\mathcal{F}_{t}, t \geq 0$, a price $p(t)>0$, a value of unemployment $V^{u}(t)$, a contract $\sigma(t)$, a market tightness $\theta(t)>0$, as well as for all entrepreneurs: consumption $c^{i}(t)$, vacancies posted $v^{i}(t)$, and resulting labor force sizes $n^{i}(\tau, t)$ for $\tau \leq t$ with economy-wide unemployment $n_{u}(t)=$ $1-\sum_{i} \int_{\tau \leq t} n^{i}(\tau, t) d \tau$ such that

1. Given $\{p(t), \sigma(t), \theta(t)\}$, for all $\mathcal{F}_{t}, t \geq 0$, the allocation $\left\{c^{i}(t), v^{i}(t), n^{i}(\tau, t)\right\}$ solves the problem

$$
\begin{aligned}
\max _{c^{i}(t), v^{i}(t)} & E_{0} \int_{0}^{\infty} e^{-\rho t} u\left(c^{i}(t)\right) d t \\
\text { s.t. } & E_{0} \int_{0}^{\infty} p(t)\left[\int_{-\infty}^{t} n^{i}(\tau, t)[z(t)-w(\tau, t)] d \tau-\kappa v^{i}(t)-c^{i}(t)\right] d t+W_{0}^{i}=0 \\
& n^{i}(\tau, t)=e^{-\delta t} n^{i}(\tau, 0) \text { for } \tau<0 \\
& n^{i}(\tau, t)=e^{-\delta(t-\tau)} q(\theta(\tau)) v^{i}(\tau) \text { for } \tau \geq 0 \\
& \text { with } W_{0}^{i}, n^{i}(\tau, 0), \sigma(\tau) \text { given for all } \tau<0
\end{aligned}
$$

2. Given $\left\{p(t), V^{u}(t)\right\}$, for all $\mathcal{F}_{t}, t \geq 0$, the contract $\sigma(t)$ maximizes the Nash product

$$
\max _{\sigma(t)}\left[V(t)-V^{u}(t)\right]^{\alpha} F_{p}(t)^{1-\alpha}
$$

\footnotetext{
${ }^{46}$ I used Matlab's collocation based bvp4c-function.
} 
where $\alpha$ is the elasticity of the matching function 47 and

$$
\begin{gathered}
V(t):=E_{t} \int_{0}^{\infty} e^{-(\rho+\delta) s}\left[u(w(t, t+s))+\delta V^{u}(t+s)\right] d s, \\
F_{p}(t):=E_{t} \int_{0}^{\infty} \frac{p(t+s)}{p(t)} e^{-\delta s}[z(t+s)-w(t, t+s)] d s .
\end{gathered}
$$

3. For all $\mathcal{F}_{t}, t \geq 0, V^{u}(t)$ is consistent with $\theta(t), \sigma(t)$ according to

$$
\begin{aligned}
\rho V^{u}(t)= & u(b)+\mu(\theta(t))\left[E_{t} \int_{0}^{\infty} e^{-(\rho+\delta) s}\left[u(w(t, t+s))+\delta V^{u}(t+s)\right] d s-V^{u}(t)\right] \\
& +\eta\left[E_{t,+} V^{u}(t)-V^{u}(t)\right]+\frac{d}{d t} V^{u}(t) .
\end{aligned}
$$

4. Goods market clearing:

For all $\mathcal{F}_{t}, t \geq 0, \sum_{i}\left[\int_{\tau=-\infty}^{t} n^{i}(\tau, t)[z(t)-w(\tau, t)] d \tau-c^{i}(t)-\kappa v^{i}(t)\right]=0$.

5. Labor market clearing: $\sum_{i} v^{i}(t)=\theta(t) n_{u}(t)$, for all $\mathcal{F}_{t}, t \geq 0$.

Proposition E.1. The bargaining equilibrium of Definition E.1 satisfies conditions 1-6 in Proposition 2.2.

Pf. Because a wage contract must be Pareto efficient between an entrepreneur and worker, equation (7) must hold. Because entrepreneurs participate in the asset market, this equation holds for their own consumption as well, implying condition 1. of Proposition 2.2. Equation (7) implies $w(t, t+s)=w(t, t)\left(e^{\rho s} \frac{p(t+s)}{p(t)}\right)^{-\frac{1}{\gamma}}$. Imposing this structure on the contract, and differentiating the log of the Nash product with respect to the initial wage $w(t, t)$ we get

$$
\begin{aligned}
& \frac{\alpha}{V(t)-V^{u}(t)} E_{t} \int_{0}^{\infty} e^{-(\rho+\delta) s} u^{\prime}(w(t, t+s))\left(e^{\rho s} \frac{p(t+s)}{p(t)}\right)^{-\frac{1}{\gamma}} d s \\
& -\frac{1-\alpha}{F_{p}(t)} E_{t} \int_{0}^{\infty} e^{-\delta s} \frac{p(t+s)}{p(t)}\left(e^{\rho s} \frac{p(t+s)}{p(t)}\right)^{-\frac{1}{\gamma}} d s \\
= & {\left[\frac{\alpha u^{\prime}(w(t, t))}{V(t)-V^{u}(t)}-\frac{1-\alpha}{F_{p}(t)}\right] E_{t} \int_{0}^{\infty} e^{-\left(\delta+\frac{\rho}{\gamma}\right) s}\left(\frac{p(t+s)}{p(t)}\right)^{1-\frac{1}{\gamma}} d s . }
\end{aligned}
$$

This implies condition 2. of Proposition 2.2. The zero profit condition follows for the same reasons as before, condition 4 . is the resource constraint and conditions 5 . and 6 . laws of motion for the value of unemployment and the measure of unemployed.

With this choice of bargaining power, the contract posting and bargaining equilibria are characterized by the same dynamics. It was shown in section 3.2. that at least in the absence of aggregate shocks this system has a unique equilibrium. The result on the equivalence of the two equilibria is known since Moen (1997) to hold in a stationary, linear utility model. It turns out to be true in this more general environment as well, as long as bargaining takes place over a long-term contract.

It is worth pointing out that although I consider a particular type of efficient wage contract, the property is more general than that. For any well-behaved efficient contracting frontier between worker and entrepreneur, the allocation of value between the parties will be the same under competitive search and bargaining, as long as the bargaining power of the worker equals the matching function elasticity 48

\footnotetext{
${ }^{47}$ This condition is often referred to as the Hosios (1990) condition.

${ }^{48}$ Consider an efficient contracting frontier $F(V)$, where $F$ is the value to the entrepreneur corresponding to the worker obtaining value $V$. Suppose $F$ is defined over some nonempty set $\left[V^{u}, \bar{V}\right]$ where $F(\bar{V})=0$ and within
} 


\section{Linear Preferences Yield Standard Employment Dynamics}

If agents have linear preferences, the incomplete markets model yields the same employment dynamics as the standard Mortensen-Pissarides model.

Proposition E.2. When $\gamma=0$, the dynamics of the incomplete markets model, characterized by system (10), (18)-(24), are such that $(\theta, \sigma)$ jump directly to steady-state. The dynamics of $m$, following $\dot{m}(t)=$ $-\delta m(t)+\mu(\theta)(1-m(t))$, are hence independent of $\Phi$ and characterized by the eigenvalue $\lambda_{1}=-\delta-\mu(\theta)$. The second stable eigenvalue $\lambda_{2}$ satisfies $\lambda_{1}<\lambda_{2}=\frac{1}{2}\left[\rho-\sqrt{\rho^{2}+\frac{4 \delta(\rho+\delta)}{1+m \Phi}}\right]<0$, where $m$, $\Phi$ are at steady-state.

Pf. Let $\gamma=0$ in system (10), (18)-(24). Defining $\tilde{Y}(t):=Y(t)+X^{2}(t)$, and using the fact that the equations (22), (23) give

$$
\tilde{Y}(t)-\left(a(t) X^{1}(t)+X^{2}(t)\right)=\frac{1-\alpha}{\alpha}\left(a(t) X^{1}(t)+X^{2}(t)\right) \Rightarrow a(t) X^{1}(t)+X^{2}(t)=\alpha \tilde{Y}(t),
$$

the law of motion for $\tilde{Y}(t)$ is

$$
\dot{\tilde{Y}}(t)=b+\mu(\theta(t)) \alpha \tilde{Y}(t)-z+(\rho+\delta) \tilde{Y}(t)
$$

where $\theta(t)$ is pinned down by $\frac{\kappa}{q(\theta(t))}=(1-\alpha) \tilde{Y}(t)$. This is an unstable differential equation as $\rho+\delta+$ $\frac{d}{d Y} \mu(\theta) \alpha \tilde{Y}>0$. Hence $\tilde{Y}(t)$ must jump immediately to steady-state. This implies that $\theta(t)$ jumps to steadystate.

To recover dynamics of the predetermined variables one needs to keep track of another jump variable, for example $X^{1}(t)$. Because $Y(t)$ also jumps to steady-state immediately, so must $X^{2}(t)$ and $\left(a X^{1}\right)(t)$. We can write the predetermined dynamics as

$$
\begin{aligned}
\dot{m}(t) & =-\delta m(t)+\mu(\theta)(1-m(t)) \\
\dot{\Phi}(t) & =\frac{\mu(\theta)(1-m(t))}{m(t)}\left[\frac{\left(a X^{1}\right)}{X^{1}(t)}-\Phi(t)\right] \\
\dot{X}^{1}(t) & =-\frac{m(t) z-\kappa \theta(1-m(t))}{1+m(t) \Phi(t)}+(\rho+\delta) X^{1}(t)
\end{aligned}
$$

where $\theta,\left(a X^{1}\right)$ are constant. The Jacobian evaluated at the steady-state is

$$
\left(\begin{array}{ccc}
-\delta-\mu(\theta) & 0 & 0 \\
0 & -\frac{\mu(\theta)(1-m)}{m} & -\frac{\mu(\theta)(1-m)}{m} \frac{\left(a X^{1}\right)}{\left(X^{1}\right)^{2}} \\
\cdots & c \frac{m}{1+m \Phi} & \rho+\delta
\end{array}\right)=\left(\begin{array}{ccc}
-\delta-\mu(\theta) & 0 & 0 \\
0 & -\delta & -\delta(\rho+\delta) \frac{\Phi}{c} \\
\ldots & c \frac{m}{1+m \Phi} & \rho+\delta
\end{array}\right)
$$

This has eigenvalues $-\delta-\mu(\theta)$ and $\frac{1}{2}\left[\rho \pm \sqrt{\rho^{2}+\frac{4 \delta(\rho+\delta)}{1+m \Phi}}\right]$.

With linear preferences, the only difference in dynamics between this model and the standard MortensenPissarides model are the wage dynamics. This has no effect on employment because the present value of wages for new workers is the same as in the Mortensen-Pissarides model, even if the timing of payments

the interval $F$ is differentiable, strictly decreasing and concave. Maintaining the assumption of a Cobb-Douglas matching technology for convenience, the FOC of the Nash product $\left(V-V^{u}\right)^{\alpha} F(V)^{1-\alpha}$ is $\frac{\alpha}{V-V^{u}}+(1-\alpha) \frac{F^{\prime}(V)}{F(V)}=$ 0 . In a competitive search framework one maximizes $q(\theta) F(V)$ such that $\mu(\theta)\left(V-V^{u}\right)$ is given. The FOC is $\frac{\alpha}{V-V^{u}}+(1-\alpha) \frac{F^{\prime}(V)}{F(V)}=0$. 
differs. The standard model does not impose the property $w(\tau, t)=a(\tau) c(t)$ for all $\tau \leq t$ as here. In the limit where $\gamma \rightarrow 0$, this timing has no justification based on optimality, but remains one of the possible wage rules that could be applied.

The second eigenvalue in PropositionE.2 is related to wage dynamics because it represents the dynamics of the average consumption share, $\Phi$. These dynamics are slow partly because only a small fraction of workers is replaced by new hires at each instant (approximately $\delta \approx 0.035$ per month) and partly because it is not optimal to change the consumption shares assigned to new hires very quickly. To shed light on the second part, consider an example: Suppose employment is at steady-state, but $\Phi$ starts out above steady-state by $\Delta \Phi$. With linear preferences, the resulting contract and labor market tightness are independent of both $m, \Phi$ and constant over time. The value of unemployment and the utility value of a new contract are hence also constant over time. This present value is $a(t) \int_{0}^{\infty} e^{-(\rho+\delta) s} c(t+s) d s$. Over time, $\Phi$ adjusts according to $\dot{\Phi}(t)=\delta[a(t)-\Phi(t)]$. How does $a(t)$ evolve? We know that any adjustment in $a$ must be offset by a change in the present value of entrepreneurial consumption. The entrepreneurial consumption is $c(t)=\frac{m z-\kappa \theta(1-m)}{1+\Phi(t) m}$. If $\Phi(t)$ is above steady-state, then $c(t)$ is below steady-state. If $\Phi(t)$ decreases over time, $c(t)$ increases. Because the optimal contract value stays constant, $a(t)$ must fall. The speeds of adjustment must be consistent, so if consumption cannot adjust quickly, $a(t)$ cannot adjust quickly.

\section{Appendix F Complete Markets Economy}

Consider changing the model environment such that i) all agents have access to the Arrow-Debreu-markets contingent on the aggregate state and ii) workers can pool their labor income, removing their idiosyncratic unemployment risk. This section shows how to solve for equilibrium in this alternative environment. In this case all agents solve consumption problems facing the same Arrow-Debreu-prices, which implies that their consumption moves together (preferences are assumed to be identical). In their labor market decisions workers maximize the present value of income, while the timing of wage payments is left indetermined.

Define probability normalized prices as $p(t):=e^{-\rho t} u^{\prime}\left(c^{A}(t)\right)$ where aggregate consumption is $c^{A}(t)=$ $m(t) z(t)+(1-m(t)) b-\kappa \theta(t)(1-m(t))$. Starting with the workers, let $I(t)$ be the present value of wages to a new worker

$$
I(t):=E_{t} \int_{0}^{\infty} e^{-\delta s} \frac{p(t+s)}{p(t)} w(t+s) d s
$$

and define $\tilde{I}(t)$ as

$$
\tilde{I}(t):=u^{\prime}\left(c^{A}(t)\right) I(t)=E_{t} \int_{0}^{\infty} e^{-(\rho+\delta) s} u^{\prime}\left(c^{A}(t+s)\right) w(t+s) d s .
$$

Then the present discounted value of unemployment $I^{u}(t)$ satisfies

$$
\begin{aligned}
I^{u}(t)= & E_{t} \int_{0}^{\infty} \frac{p(t+s)}{p(t)} e^{-\int_{0}^{s} \mu(\theta(t+\tau)) d \tau} \times \\
& {\left[b+\mu(\theta(t+s))\left[I(t+s)+E_{t+s} \int_{0}^{\infty} e^{-\delta \tau} \frac{p(t+s+\tau)}{p(t+s)} \delta I^{u}(t+s+\tau) d \tau\right]\right] d s . }
\end{aligned}
$$

I define the auxiliary variables

$$
Z(t):=E_{t} \int_{0}^{\infty} e^{-\delta s} \delta \frac{p(t+s)}{p(t)} I^{u}(t+s) d s-I^{u}(t),
$$


$\tilde{I}^{u}(t):=u^{\prime}\left(c^{A}(t)\right) I^{u}(t)$ and $\tilde{Z}(t):=u^{\prime}\left(c^{A}(t)\right) Z(t)$. Using these, we have

$$
\begin{aligned}
\tilde{I}^{u}(t)= & E_{t} \int_{0}^{\infty} e^{-\rho s-\int_{0}^{s} \mu(\theta(t+\tau)) d \tau} \times \\
& {\left[u^{\prime}\left(c^{A}(t+s)\right) b+\mu(\theta(t+s))\left[\tilde{I}(t+s)+\tilde{Z}(t+s)+\tilde{I}^{u}(t+s)\right]\right] d s . }
\end{aligned}
$$

Hence,

$$
\rho \tilde{I}^{u}(t)=u^{\prime}\left(c^{A}(t)\right) b+\mu(\theta(t))[\tilde{I}(t)+\tilde{Z}(t)]+\eta\left[E_{t,+} \tilde{I}^{u}(t)-\tilde{I}^{u}(t)\right]+\dot{\tilde{I}}^{u}(t),
$$

and

$$
(\rho+\delta) \tilde{Z}(t)=-u^{\prime}\left(c^{A}(t)\right) b-\mu(\theta(t))[\tilde{I}(t)+\tilde{Z}(t)]+\eta\left[E_{t,+} \tilde{Z}(t)-\tilde{Z}(t)\right]+\dot{\tilde{Z}}(t) .
$$

On the hiring side, define the present discounted value of output $Y(t):=E_{t} \int_{0}^{\infty} e^{-\delta s} \frac{p(t+s)}{p(t)} z(t+s) d s$ and also $\tilde{Y}(t):=E_{t} \int_{0}^{\infty} e^{-(\rho+\delta) s} u^{\prime}\left(c^{A}(t+s)\right) z(t+s) d s$. The zero profit condition for vacancy-posting now reads: $q(\theta(t)) \frac{[\tilde{Y}(t)-\tilde{I}(t)]}{u^{\prime}\left(c^{A}(t)\right)}=\kappa$.

The labor market problem reads

$$
\begin{aligned}
& \max _{\theta(t), \tilde{I}(t)} q(\theta(t))[\tilde{Y}(t)-\tilde{I}(t)] \text { s.t. } \\
& \rho \tilde{I}^{u}(t)=u^{\prime}\left(c^{A}(t)\right) b+\mu(\theta(t))[\tilde{I}(t)+\tilde{Z}(t)]+\eta\left[E_{t,+} \tilde{I}^{u}(t)-\tilde{I}^{u}(t)\right]+\dot{\tilde{I}}^{u}(t),
\end{aligned}
$$

and the optimum is characterized by $\tilde{Y}(t)-\tilde{I}(t)=\frac{1-\alpha}{\alpha}[\tilde{I}(t)+\tilde{Z}(t)]$.

This yields the system:

$$
\begin{aligned}
\dot{m}(t) & =-\delta m(t)+\mu(\theta(t))(1-m(t)), \\
\dot{\tilde{Z}}(t) & =(\rho+\delta) \tilde{Z}(t)+u^{\prime}\left(c^{A}(t)\right) b+\mu(\theta(t))[\tilde{I}(t)+\tilde{Z}(t)]-\eta\left[E_{t,+} \tilde{Z}(t)-\tilde{Z}(t)\right], \\
\dot{\tilde{Y}}(t) & =(\rho+\delta) \tilde{Y}(t)-u^{\prime}\left(c^{A}(t)\right) z(t)-\eta\left[E_{t,+} \tilde{Y}(t)-\tilde{Y}(t)\right],
\end{aligned}
$$

where

$$
\begin{aligned}
& c^{A}(t)=m(t) z(t)+(1-m(t)) b-\kappa \theta(t)(1-m(t)), \\
& q(\theta(t)) \frac{[\tilde{Y}(t)-\tilde{I}(t)]}{u^{\prime}\left(c^{A}(t)\right)}=\kappa, \\
& \tilde{Y}(t)-\tilde{I}(t)=\frac{1-\alpha}{\alpha}[\tilde{I}(t)+\tilde{Z}(t)] .
\end{aligned}
$$

To solve this system, one can further define $\tilde{S}(t):=\tilde{Y}(t)+\tilde{Z}(t)$ to arrive at

$$
\begin{aligned}
\dot{m}(t) & =-\delta m(t)+\mu(\theta(t))(1-m(t)), \\
\dot{\tilde{S}}(t) & =(\rho+\delta) \tilde{S}(t)+u^{\prime}\left(c^{A}(t)\right)(b-z(t))+\mu(\theta(t)) \alpha, \tilde{S}(t)-\eta\left[E_{t,+} \tilde{S}(t)-\tilde{S}(t)\right],
\end{aligned}
$$

where

$$
\begin{aligned}
& c^{A}(t)=m(t) z(t)+(1-m(t)) b-\kappa \theta(t)(1-m(t)), \\
& q(\theta(t))(1-\alpha) \frac{\tilde{S}(t)}{u^{\prime}\left(c^{A}(t)\right)}=\kappa .
\end{aligned}
$$


As stated, the timing of wage payments is not pinned down here. To derive wage implications, one possibility is to impose that all workers get the same wage 49 Under this assumption, the present value of wages of old workers always equals that of newly hired workers, $I$. Given the path of $I(t)$, contract wages must satisfy

$$
(\rho+\delta) \tilde{I}(t)=u^{\prime}\left(c^{A}(t)\right) w(t)+\eta\left[E_{t,+} \tilde{I}(t)-\tilde{I}(t)\right]+\dot{\tilde{I}}(t) .
$$

Using $\tilde{I}(t)=\tilde{Y}(t)-(1-\alpha) \tilde{S}(t)$ and the laws of motion we get

$$
\begin{aligned}
w(t) & =\frac{(\rho+\delta) \tilde{I}(t)-\eta\left[E_{t,+} \tilde{I}(t)-\tilde{I}(t)\right]-\dot{\tilde{I}}(t)}{u^{\prime}\left(c^{A}(t)\right)} \\
& =z(t)-(1-\alpha)\left[z(t)-b-\mu(\theta(t)) \alpha \frac{\tilde{S}(t)}{u^{\prime}\left(c^{A}(t)\right)}\right] \\
& =(1-\alpha) b+\alpha(z(t)+\kappa \theta(t)) .
\end{aligned}
$$

\footnotetext{
${ }^{49}$ This corresponds to wages being determined by continual re-bargaining, if the bargaining share of workers coincides with the matching function elasticity i.e. the Hosios (1990) condition holds.
} 